\section{Journal of Educational}

and Psychological Sciences

Volume (6), Issue (2) : 30 Jan 2022

P: $138-161$

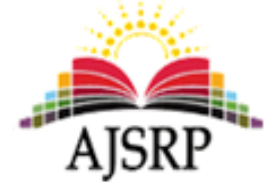

ISSN: 2522-3399

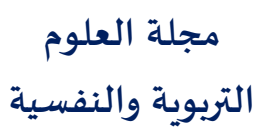

المجلد (6)، العدد (2) : 30 يناير 2022 م

ص: 138 - 161

\title{
Future anxiety during the switch to distance learning during the Coronavirus (COVID-19) pandemic and its relationship to some variables among secondary school students in Madinah
}

\author{
Enas Murdhi Naji Al-Harbi \\ Faculty of Education || Taibah University || KSA
}

\begin{abstract}
This study aimed to identify the degree of future anxiety in light of the shift to distance education during COVID19 among secondary school students in Al Madinah Al Munawwarah and to identify the differences in the degree of future anxiety due to some demographic variables (gender - major- income level). The study sample included (403) female and male secondary school students in Al Madinah Al Munawwarah, in the second and third secondary grades, who were chosen by the simple random sampling. In order to achieve the objectives of the study, the researcher adopted the Analytical descriptive approach. The researcher used the Future Anxiety Scale prepared by (Shuqair, 2005).

The study concluded that there was simple future anxiety in light of the shift to distance education during COVID-19 among second and third secondary school students in Al Madinah Al Munawwarah، and there were no statistically significant differences at (0.05) level in the degree of future anxiety in light of the shift to distance education during COVID-19 due to demographic variables (gender, major, income level) variable among the second and third secondary school students in Al Madinah Al Munawwarah. In light of the above-mentioned results, the researcher recommends that Ministry of Education at Saudi Arabia has to continue implementing the distant education, as the results of the current study showed that it does not, significantly, affect future anxiety levels among high school students.
\end{abstract}

Keywords: Future Anxiety - Distance Learning - Coronavirus pandemic - COVID-19 - Secondary School.

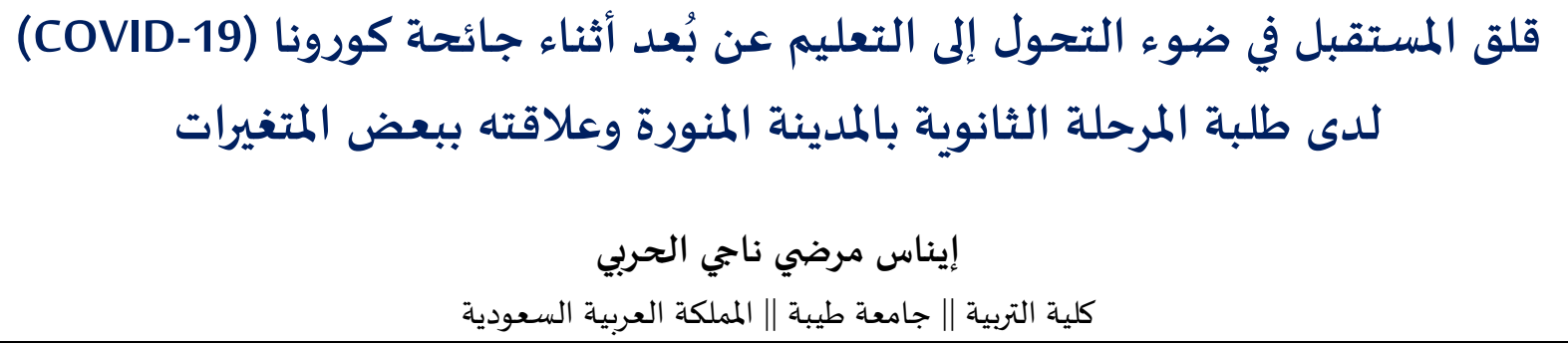

المستخلص: هدفت الدراسة الحالية إلى التعرف على درجة قلق المستقبل في ضوء التحول إلى التعليم عن بُعد أثناء جائحة كورونا (COVID-19) لدى طلبة المرحلة الثانوية بالمدينة المنورة، والتعرف على الفروق في درجة قلق المستقبل والتي تُعزى إلى بعض المض المتفيرات الديموغرافية (الجنس - التخصص - مستوى دخل الأسرة)، وتكونت عينة الدراسة من (403) طالبًا وطالبة من طلبة المبالة المرحلة الثانوية

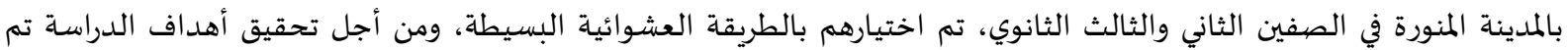
استخدام المنهج الوصفي التحليلي، كما تم استخدام مقياس قلق المستقبل من إعداد (شقير، 2005)، وتوصلت نتائج الدراسة إلى وجود

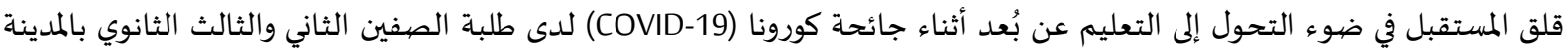
المنورة بدرجة بسيطة، كما توصلت إلى عدم وجود فروق دالة إحصيائيًا عند مستوى (0.05) في درجة قلق المستقبل في ضوء التحول إلى إلى

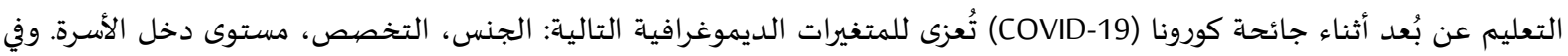


ضوء النتائج التي أسفرت عنها الدراسة توصي الباحثة وزارة التعليم في المملكة العربية السعودية، بمواصلة الآلية التي تتبعها في تطبيق

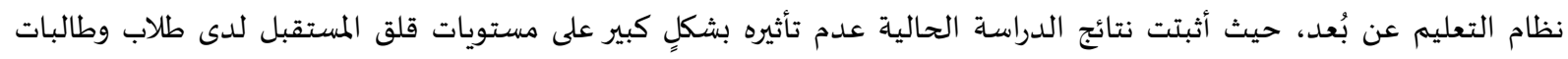

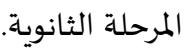

الكلمات المفتاحية: قلق المستقبل - التعليم عن بُعد - جائحة كورونا - كوفيد19 - طلبة المرحلة الثانوية.

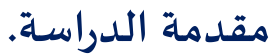

يعيش العالم اليوم أزمة عالمية والتي بدأ ظهورها في نهاية عام 2019م في مدينة ووهان بالصين، حيث بدأ

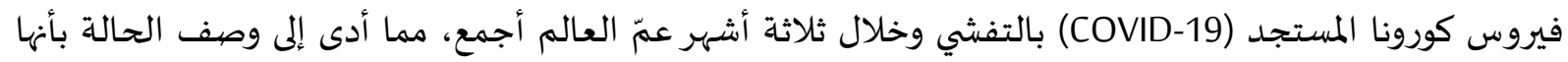
جائحة أو أزمة. وتشير كلمة أزمة إلى لحظات الضيق والشدة (إبراهيم وآخرون، 1973)، كما تشير إلى التغيير المفاجئ،

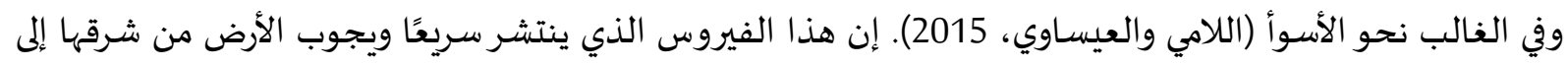

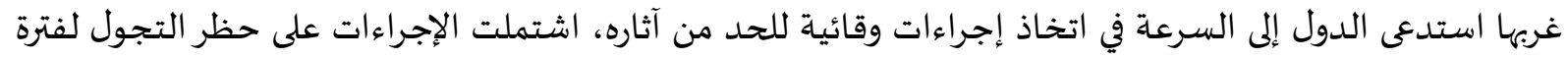
من الزمن، والفحص المستمر، وقيود السفر، وإغلاق كافة المؤسسات، والتي من ضمنها المؤسسات التعليمية. وكما يحدث دائمًا في الأزمات تبرز التحديات وفرص التحول، واليوم في أزمة جائحة كورونا، التحدي الأبرز هو في كيفية

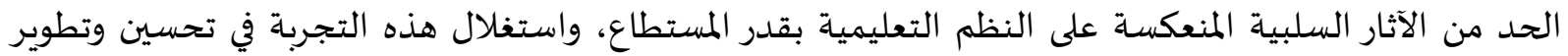
التعليم (قناوي، 2020).

ويعكس خطر الأزمة على النظم التعليمية، نسب وإحصائيات التعليم في بداية جائحة فيروس كورونا، فبحسب إحصائيات البنك الدولي اتضيح أن 146 دولة أغلقت مدارسها على مستوى العالم، و انقطع 1.6 مليار طفل

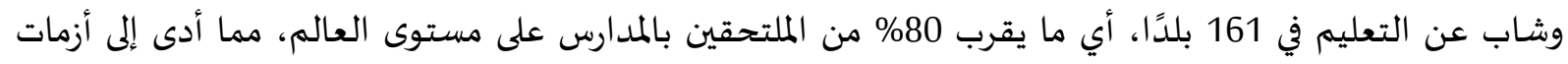

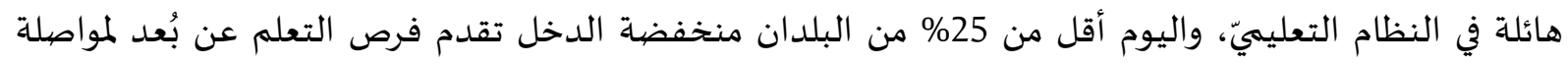

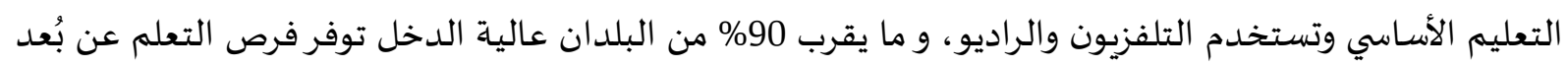

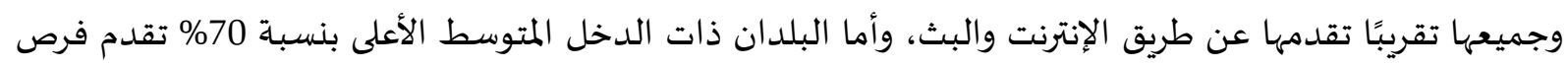

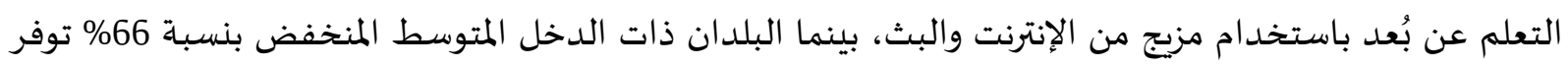

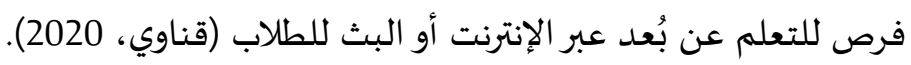

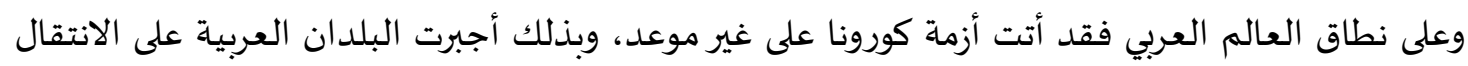

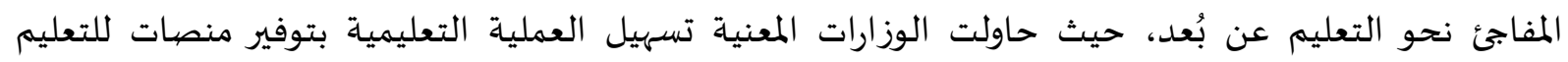

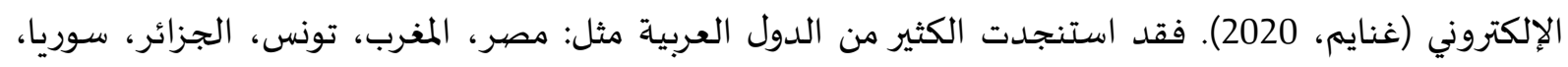

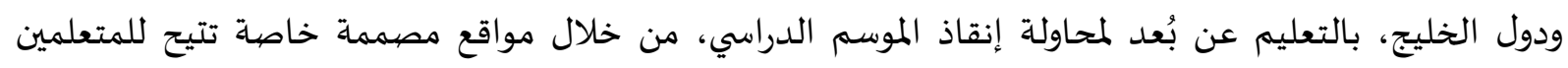
متابعة دروسهم، أو عن طريق وسائل الإعلام الجماهيري كالإذاعات الحكومية والقنوات التلفزيونية (الخميسي،

وفي المملكة العبية السعودية تم تعليق الحضور إلى مدارس التعليم العام، والجامعات في كافة مناطق

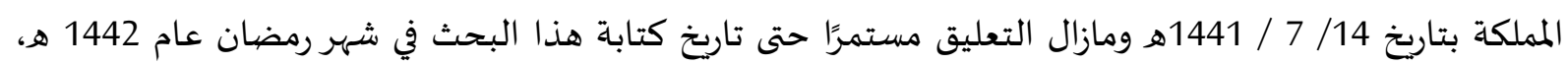

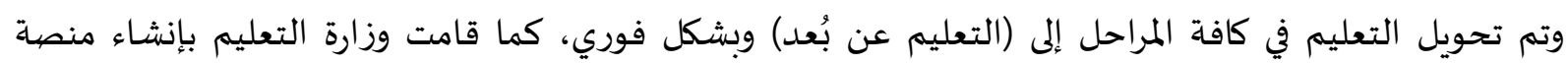

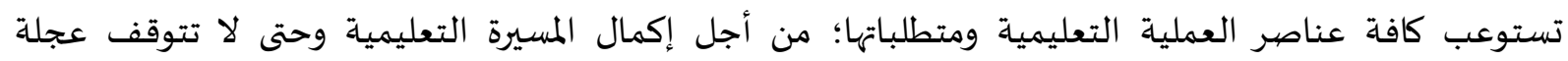

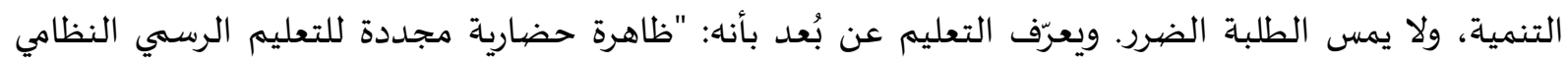

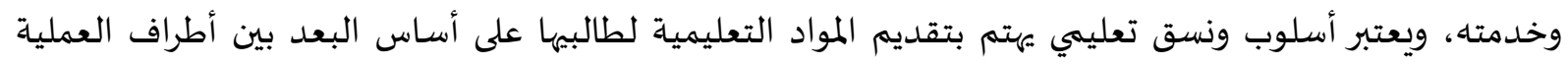


التعليمية؛ أي بين الطالب والأستاذ" (خفاجي، 2015، 13). ويذكر الدهشان (2020) في تطلعاته لمستقبل التعليم بعد

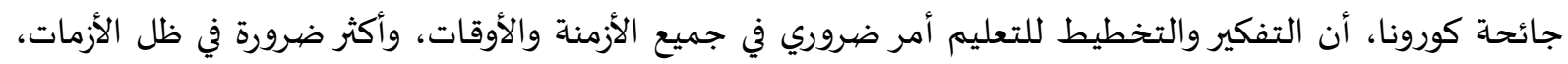

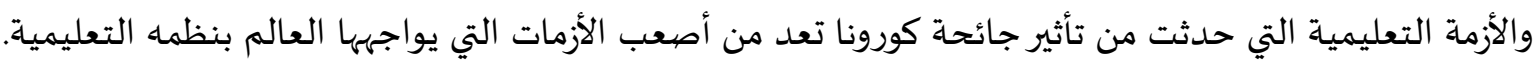

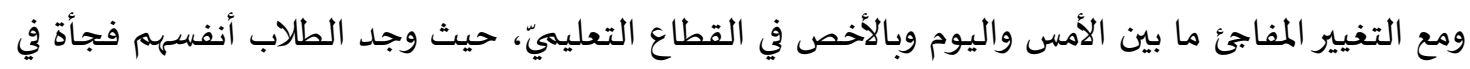

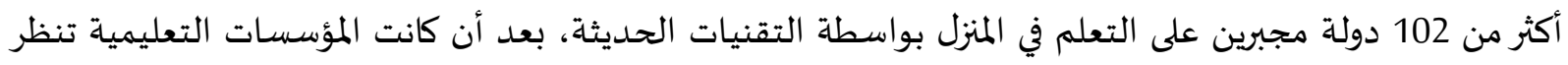

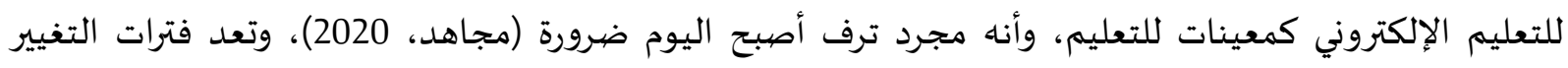

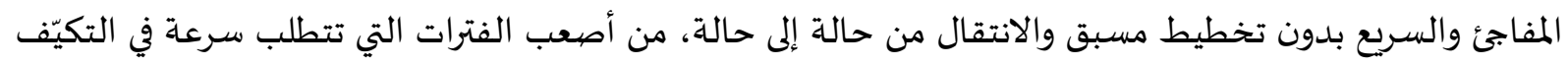

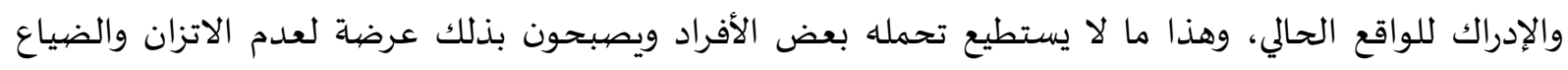

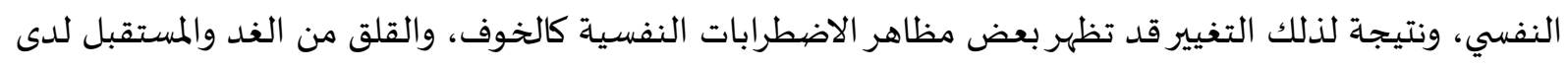

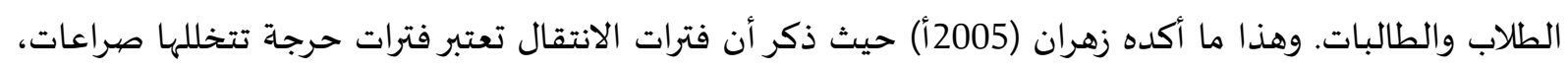

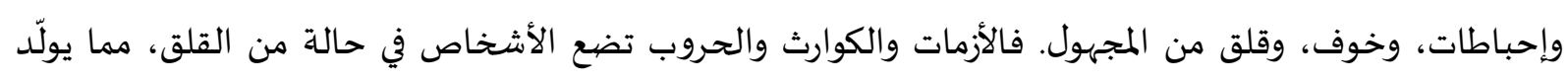

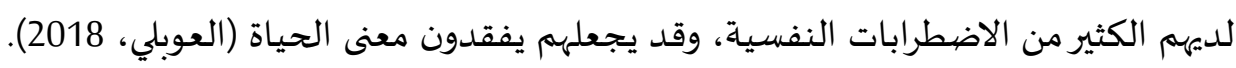

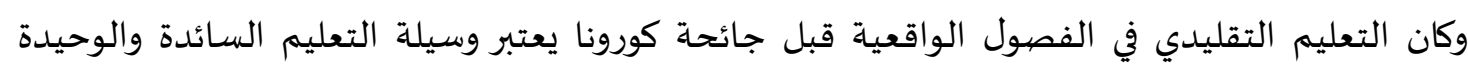

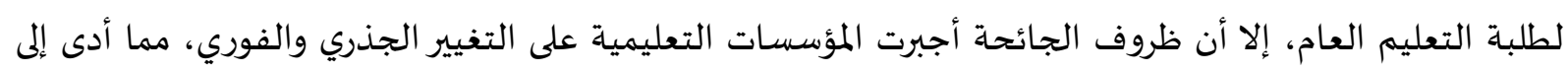

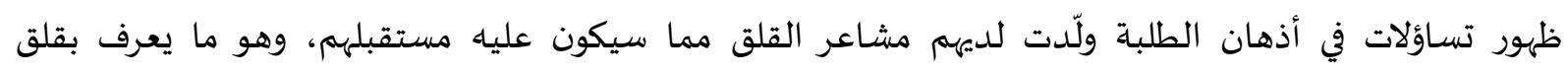
المستقبل. ولأن مفهوم قلق المستقبل جزء من مفهوم القلق العام، يعرّف القلق بشكلٍ عام بأنه: "حالة توتر شامل

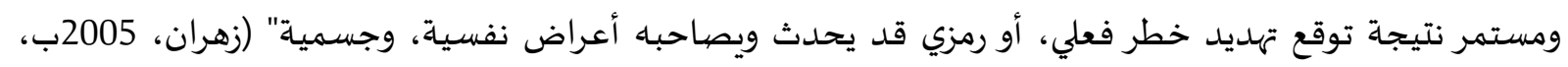

ويشير زالسكي Zaleski (1996) إلى أن جميع أنواع القلق لها بُعد مستقبلي يتحدد ضمن فترات زمنية قصيرة

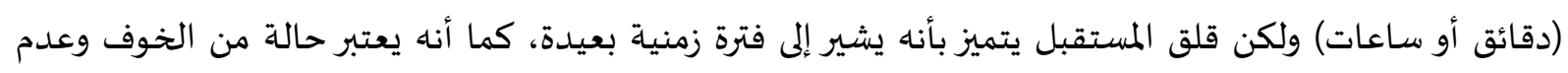

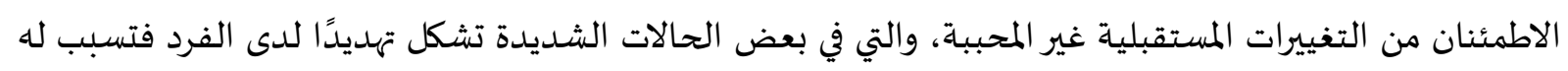

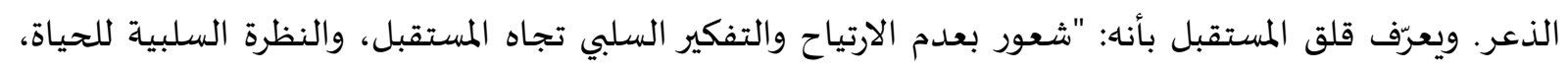

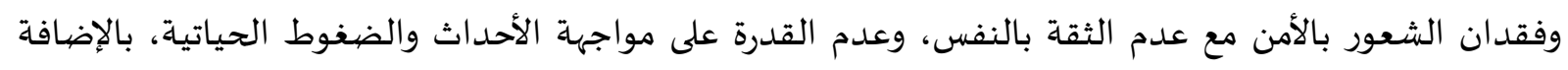

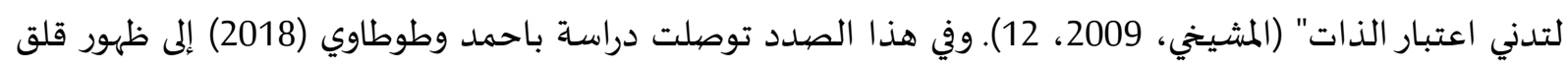
المستقبل لدى طلبة التعليم عن بُعد بدرجة متوسطة في مركزي تيزي وزو وبجاية في الجزائر، مما اعتبره الباحثان

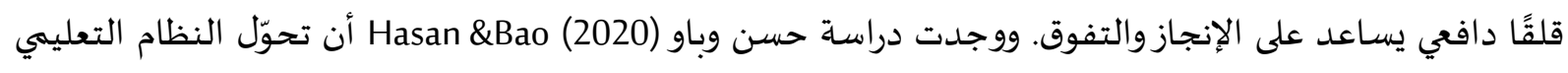

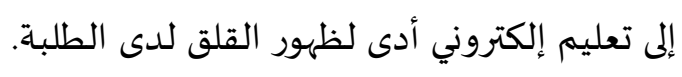
واختلفت الدراسات في تحديد المتغيرات المؤثرة على قلق المستقبل، التي ربما تزيد أو تخفض من من مستواه

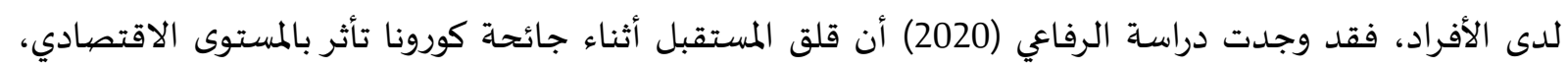

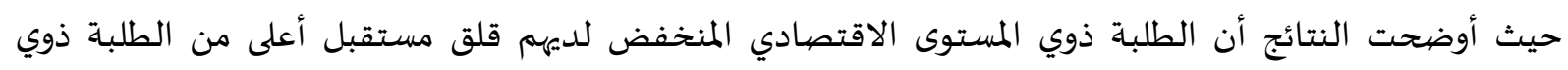

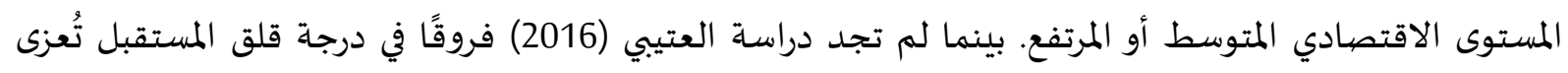

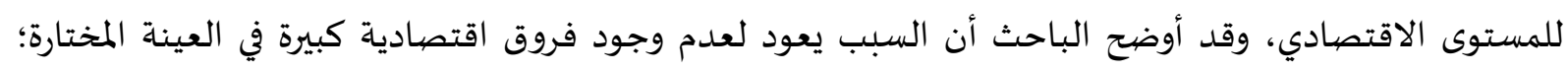
فقد تشكلت من منطقة واحدة، مما يدل على تقارب المستوى الاقتصادي الادفي بينهم. وكذلك بالنسبة لمتغيري الجنس، والتخصص، فقد تبيّن من خلال دراسة عابد (2015) أن الذكور أعلى قلقًا

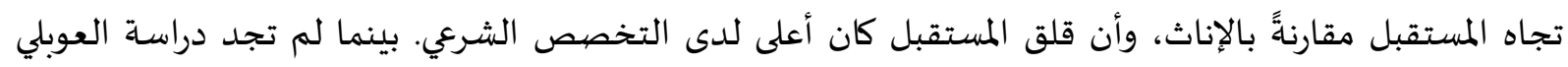


(2018) فروقًا تُعزى للجنس في مستوى قلق المستقبل. ولم تجد دراسة وادة (2019) فروقًا تُعزى للتخصص في مستوى قلق المستقبل. وتكمن خطورة ظاهرة قلق المستقبل في تأثيرها السلبي على طموح الطلبة، فتعيق تقدمهم، وتشوه إدراكهم لقدراتهم، وإمكانياتهم الواسعة، حيث وجدت دراسة العتيبي (2012) علاقة دالة سالبة بين قلق المستقبل، وكلِّ من دافعية الإنجاز وتقدير الذات لدى طلاب المرحلة الثانوية. وتوصلت دراسة الحربي (2018) إلى وجود علاقة ارتباطية المانية

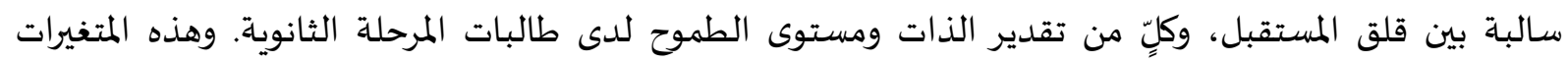

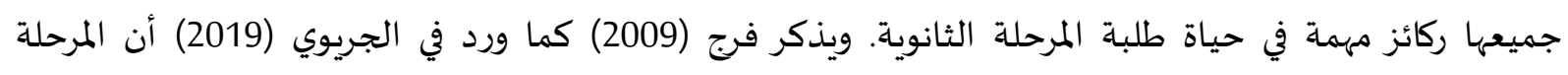

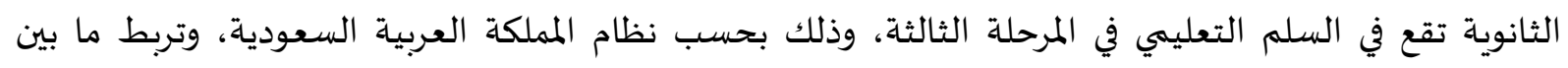
التعليم العالي والتعليم الأساسي، حيث تمتد الدراسة في هذه المرحلة إلى ثلاث سنوات، كما أن أعمار الطلبة الماتة تكونة

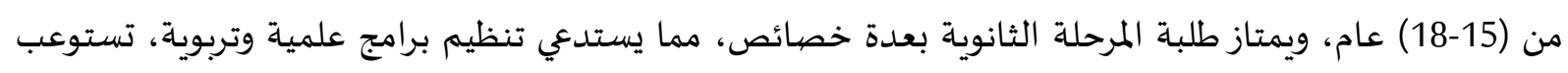
التجديدات وتحقق الطموحات.

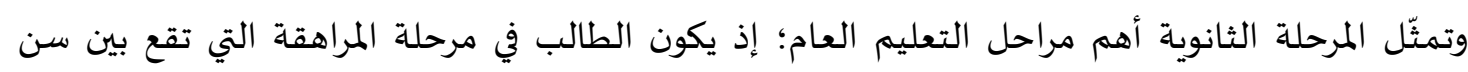

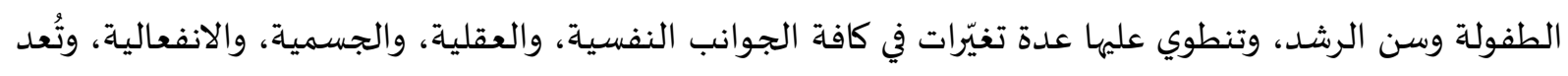

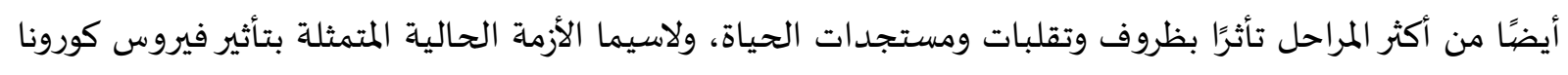
(COVID-19)

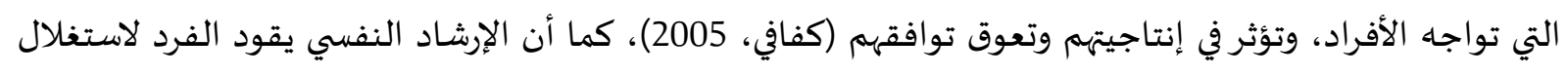

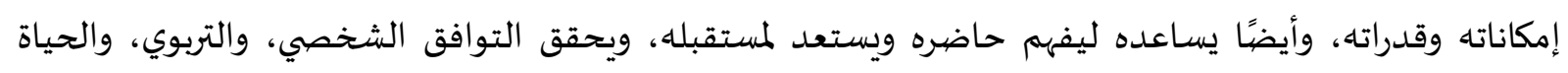
السعيدة (زهران، 2005أ).

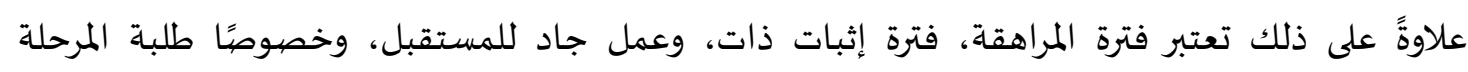

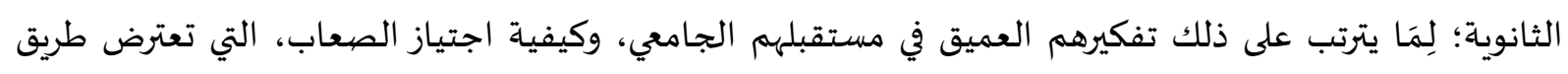

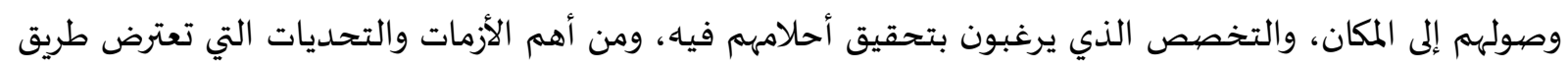

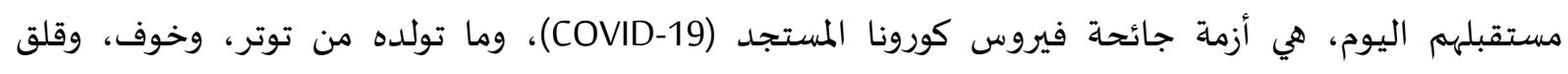

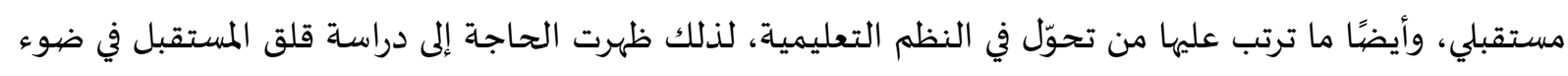

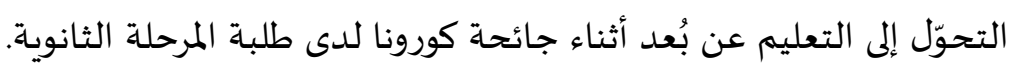

مشكلة الدراسة: تعد جائحة فيروس كورونا المستجد (COVID-19) في سنة 2020-2021م من أبرز الأزمات على الساحة

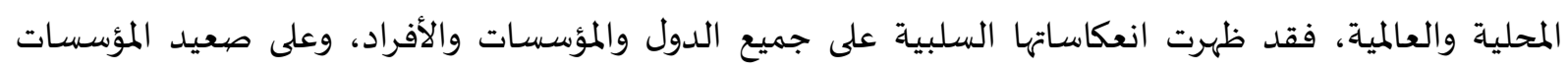

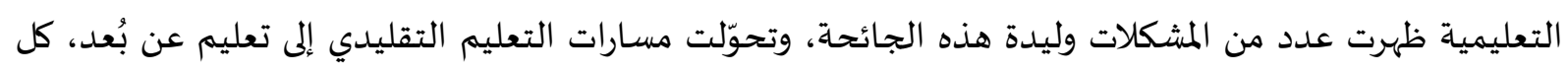

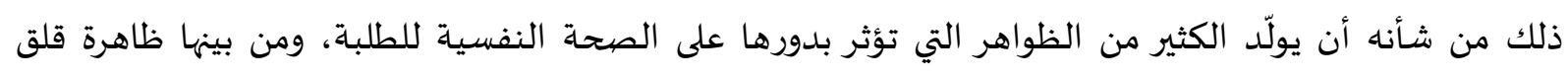

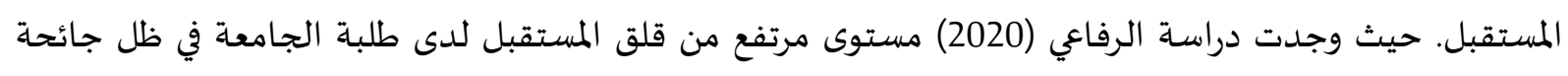

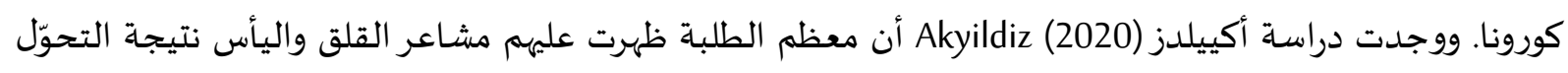

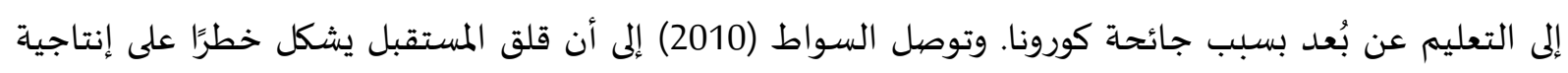

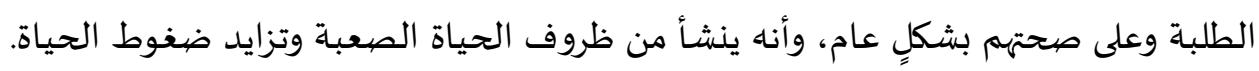


بناء على ما سبق؛ يمكن صياغة مشكلة الدراسة في التساؤل الرئيس:

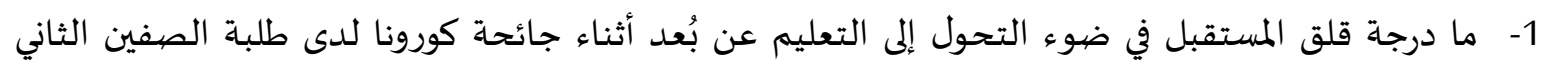

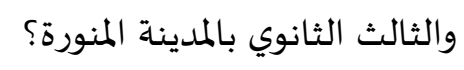

وينبثق منه الأسئلة الفرعية التالية:

1- - هل توجد فروق دالة إحصائيًا في درجة قلق المستقبل في ضوء التحول إلى التعليم عن بُعد أثناء جائحة

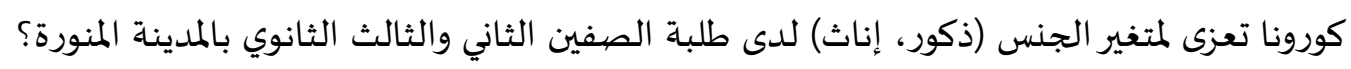

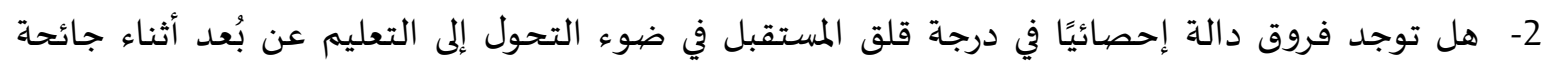

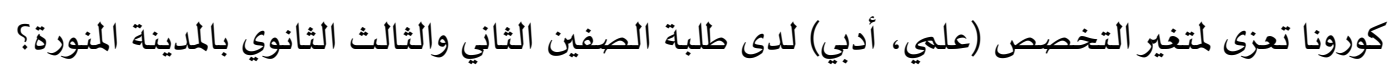

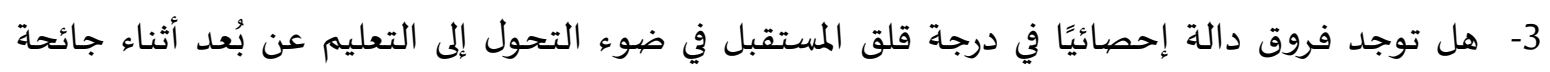

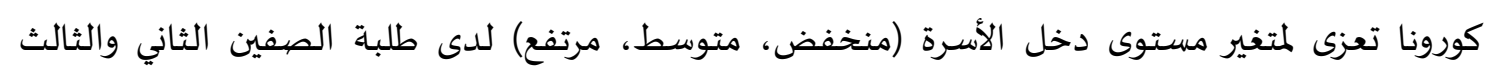

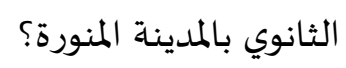

أهداف الدراسة:

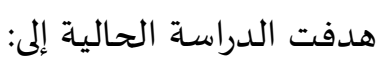

1- التعرف على درجة قلق المستقبل في ضوء التحول إلى التعليم عن بُعد أثناء جائحة كورونا لدى طلبة الصفين الثاني والثالث الثانوي بالمدينة المنورة. 2- التعرف على الفروق في درجة قلق المستقبل في ضوء التحول إلى التعليم عن بُعد أثناء جائحة كورونا والتي

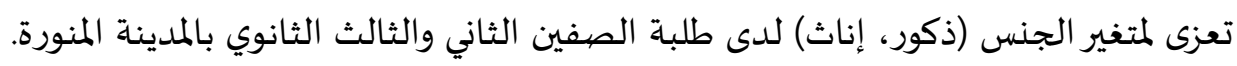

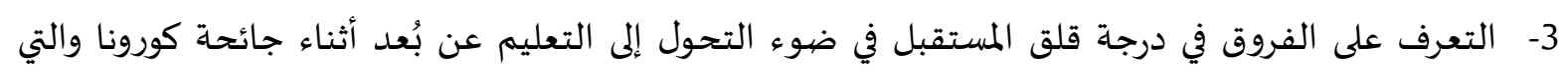

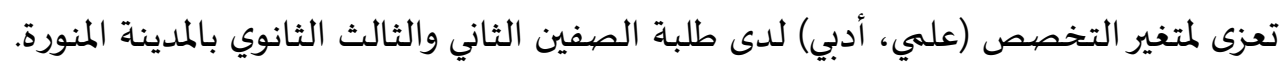

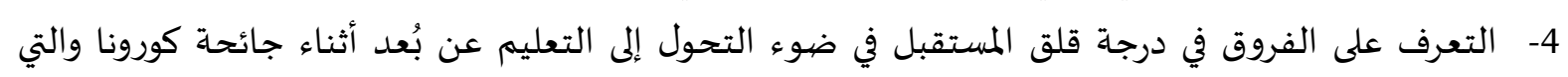
تعزى لمتغير مستوى دخل الأسرة (منخفض، متوسط، مرتفع) لدى طلبة الصفين الثاني والثالث الثانوي بالمدينة المنورة.

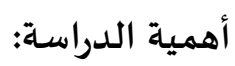

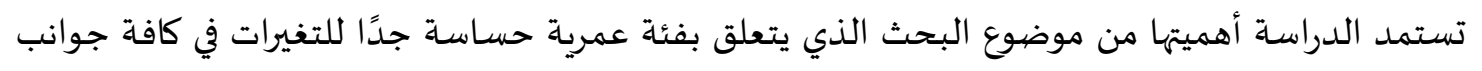
الحياة، ولا سيما التغيرات النفسية، ومن الآثار المترتبة على الأزمة العالمياة لفيروس كورونا المستجدي (COVID-19) وتداعياتها على النظم التعليمية. الأهمية النظرية للدراسة

$$
\text { تتلخص الأهمية النظرية للدراسة في الآتي: }
$$

- أهمية متغير قلق المستقبل، ودوره في التأثير السلبي على جوانب الحياة كافة، لدى فئة عمرية مهمة، وهم

$$
\text { طلاب وطالبات المرحلة الثانويـة. }
$$

- توضح الدراسة الحالية أهم التحديات، والمميزات الناجمة عن التحوّل التعليمي، والذي يتبنى نظام (التعليم عن بُعد)، وذلك بعرض ما توصلت إلية نتائج الدراسات السابقة في هذا الميدات الماندان. 
- تعتبر الدراسة الحالية من الدراسات الحديثة التي تواكب مجريات العصر على البيئة السعودية، وفي المدينة المنورة تحديدًا -على حد علم الباحثة-.

- ـ تبيّن الدراسة الحالية، الانعكاسات السلبية على المؤسسات التعليمية، من تأثير الأزمة العالمية الحالية

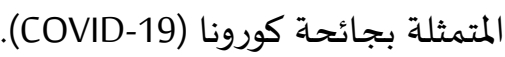

الأهمية التطبيقية للدراسـة:

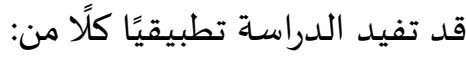

- العاملين في مجال الإشاد النفسي والتربوي، وذلك من خلال إمدادهم بنتائج ظاهرة قلق المستقبل المترتبة

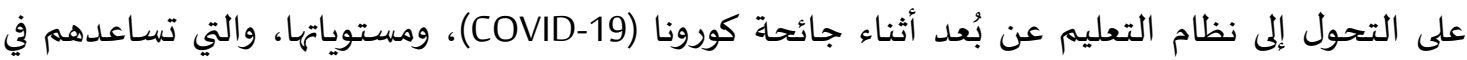
تصميم برامج إرشادية للطلاب والطالبات. - - التربويين والمعلمين، حيث قد تسهم نتائج الدراسة في مساعدتهم لتفهم المرحلة الحرجة، والانتقالية التي

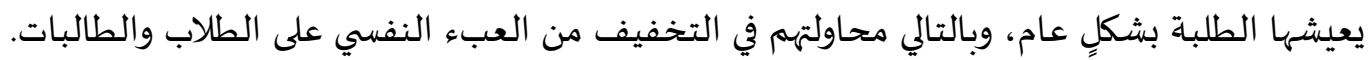
- - مالباحثين في المجالات النفسية والتربوية، حيث قد تعتبر نتائج الدراسة نقطة انطلاق لدراسات قادمة، ومكملة للدراسة الحالية.

حدود الدراسة: الحدود الموضوعية: تمت دراسة قلق المستقبل في ضوء التحوّل إلى التعليم عن بُعد أثناء جائحة كورونا (COVID-19) وعلاقتاه ببعض المتغيرات الديموغرافية (الجنس، التخصص، مستوى دخل الأسرة). الحدود البشرياة: طلبة الصفين الثاني والثالث الثانوي بالقسمين (العلمي-الأدبي). الحدود المكانية: عدد من مدارس المرحلة الثانوية بالمدينة المنورة. الحدود الزمانية: خلال الفصل الدراسي الثاني من العام الدراسي (2021-2020م). مصطلحات الدراسة: قلق المستقبل "FUTURE ANXIETY": - اصطلاحًا: اضطراب نفسي ناتج عن خبرات الفرد الماضية والغير سارّة، يحدث فياه تحريف وتشويه للذات

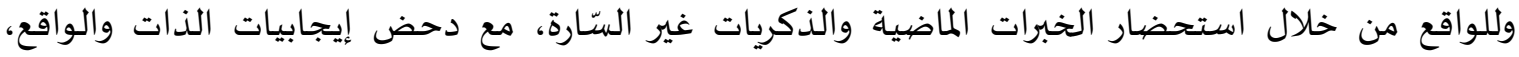
وتضخيم سلبياتهما، تجعل الفرد في حالة من عدم الأمن والتوتر، وقد تدفعه لتدمير الذات، وتعميم الفشل، والعجز الواضح، وتوقع الكوارث، وحالة من التشاؤم تجاه المستقبل، والخوف من المشكلات الاقتصادية، والاجتماعية المتوقعة، وقلق التفكير في المستقبل، وقلق الموت، واليأس، والأفكار الوسواسية (شقير، 2005، 5) - ويعّرف أيضًا بأنه: حالة انفعالية تتصف بأنها غير سارّة، تولد لدى الفرد عندما يفكر بالأمور المستقبلية الغامضاة، أو عندما يواجه مواضيع وأحداث صعبة التعامل بالنسبة إليه (قليوبي، 2019، 192). إجرائيًا: هي الدرجة الكلية التي يحصل عليها طلبة المرحلة الثانوية على مقياس قلق المستقبل من إعداد (شقير، 
التعليم عن بُعد "DISTANCE LEARNING": - اصطلاحًا: نظام تعليمي قائم على أساس تباعد المعلم عن المتعلم، في الزمان، أو المكان، أو كليهما، بحيث لا يوجد

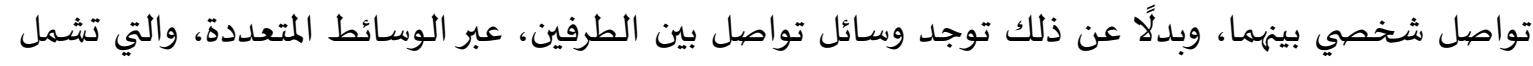

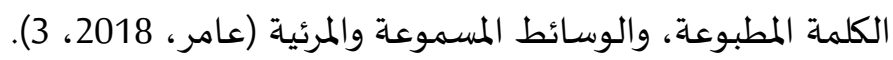

فيروس كورونا المستجد "COVID-19": - اصطلاحًا: فيروس ينتهي إلى فيروسات كورونا واسعة الانتشار، تسبب أمراض متفاوتة الشدة، و (COVID-19)

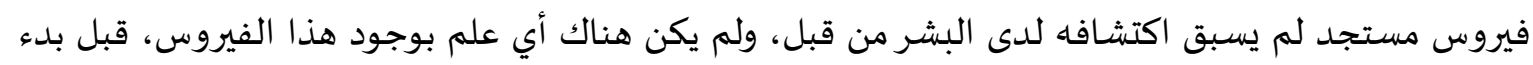

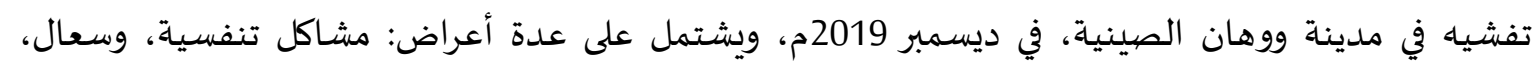

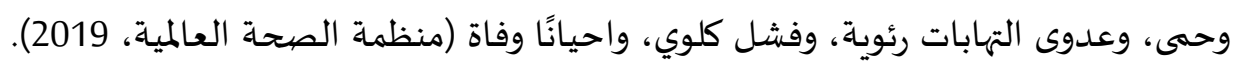

المرحلة الثانوية "Secondary School

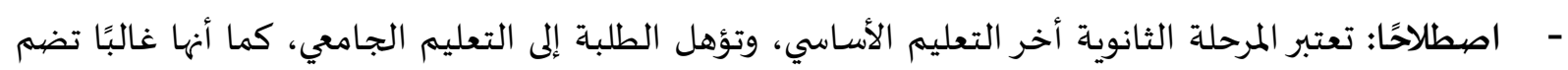

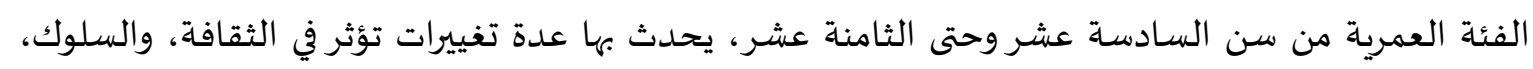

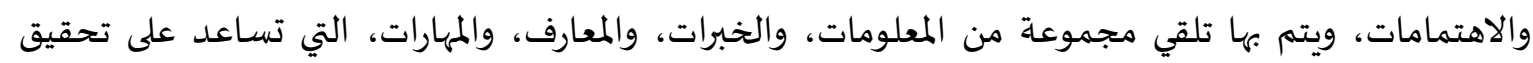

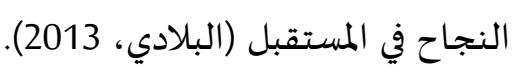

2- 2 - الدراسـات السـابقة. سيتم استعرض الدراسات السابقة بناءً على الخط الزمني من الأقدم إلى الأحدث، وتم تقسيم الدراسات

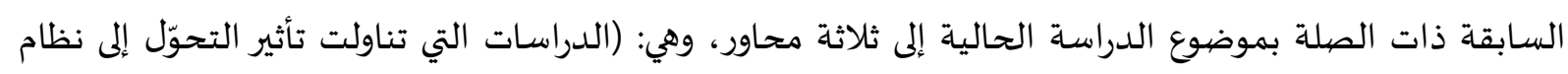

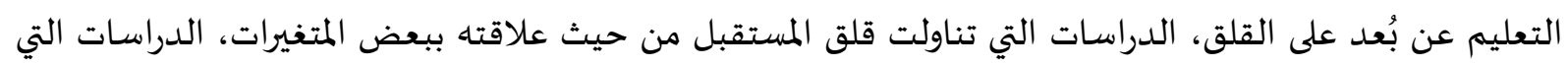
تناولت قلق المستقبل وعلاقته بالأزمات)، وفيما يلي استعراضهيم بشكل التعل متتالي:

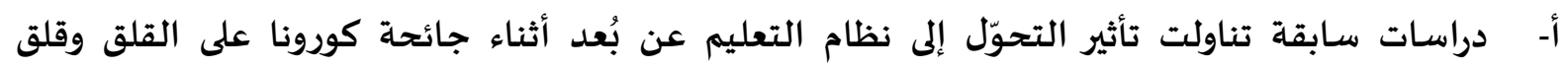
أمستقبل: - أجرى حسن وباو Hasan \&Bao (2020 دراسة بعنوان: "تأثير تصورات الطلاب حول رداءة التعلم الإلكتروني

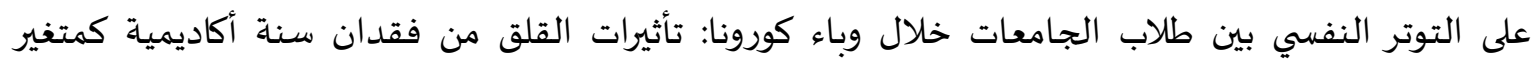

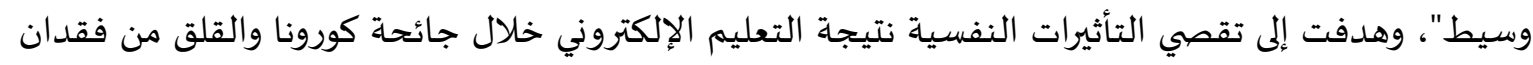

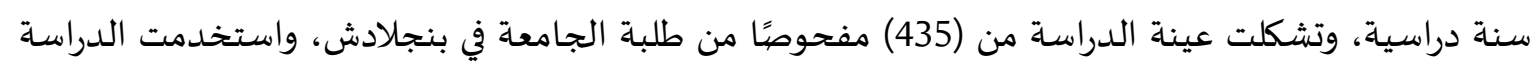

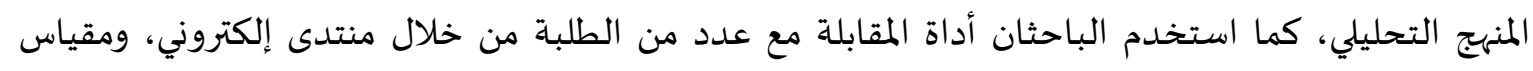

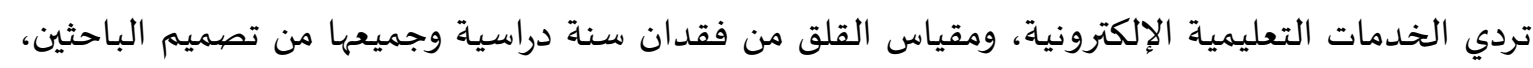

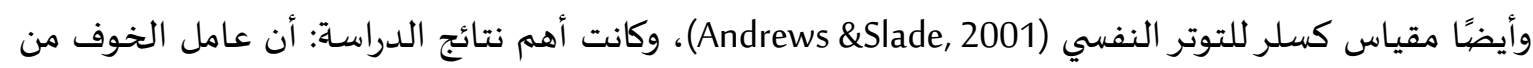

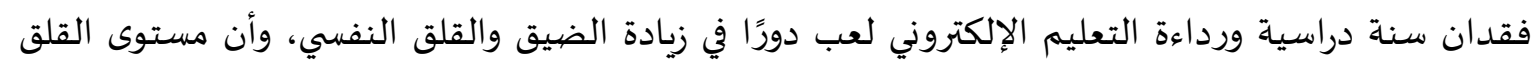

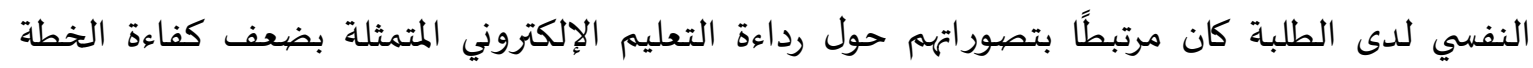
الدراسية، والتطور التعليمي. وأجرى أكييلدز (2020) Akyildiz دراسة بعنوان: "آراء طلاب الجامعات حول التعليم عن بُعد في الجائحة: مناقشة جماعية مركزة"، وهدفت إلى معرفة تصورات طلاب الجامعات التركية عن التعليم أثناء وباء كورونا، 
وتشكلت عينة الدراسة من (12) طالبًا وطالبة من جميع المراحل، كما تم استخدام أداة المقابلة والمناقشة مع

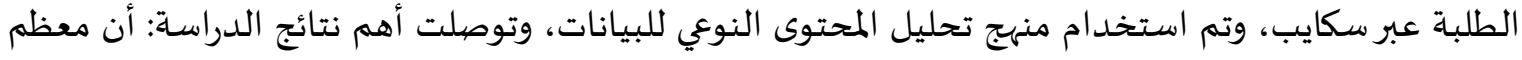

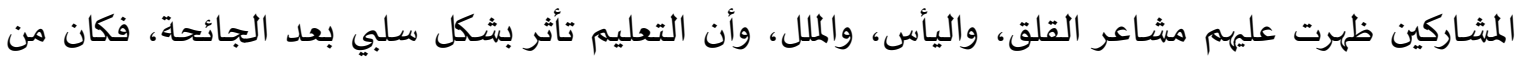

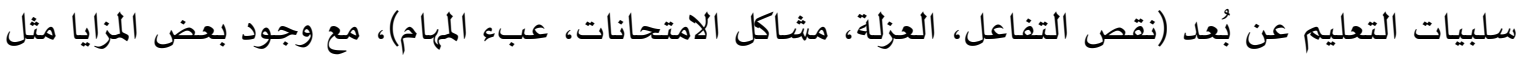
(مرونة الوقت، تحمل الطلبة مسؤولية التعليم). - كما قامت الرفاعي (2020) بإجراء دراسة بعنوان: "قلق المستقبل لدى الشباب الجامعيين بظل جائحة كورونا

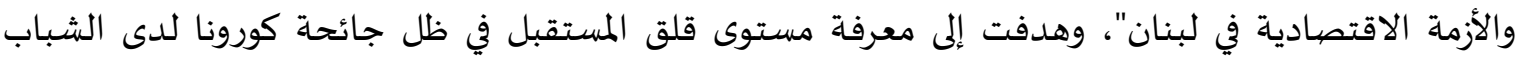

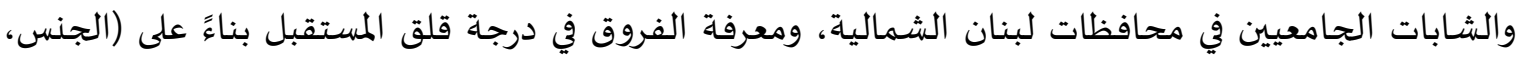

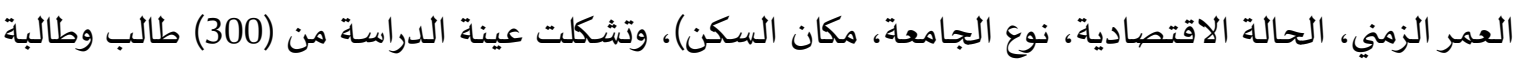

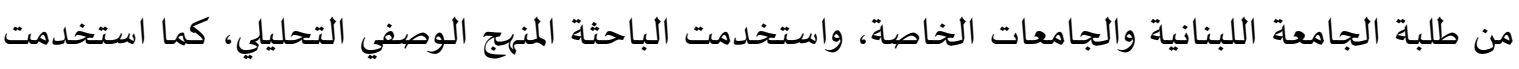

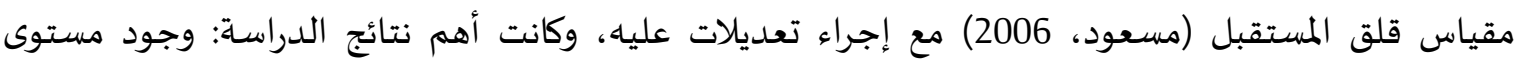

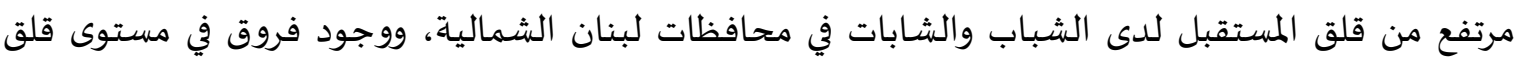

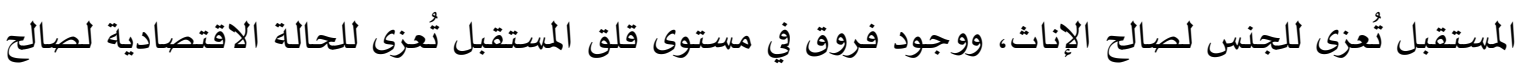

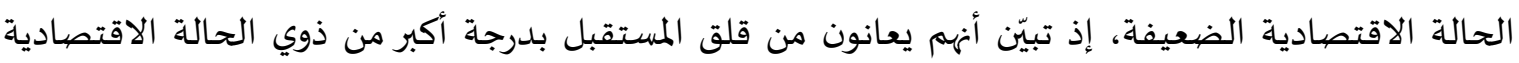
المرتفعة والمتوسطة.

ب- دراسات سابقة تناولت قلق المستقبل من حيث علاقته ببعض المتنغيرات:

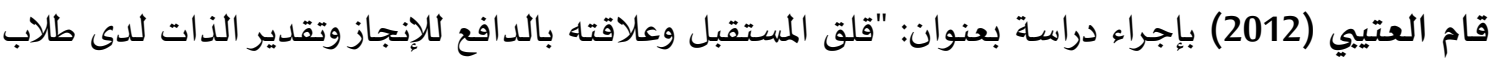

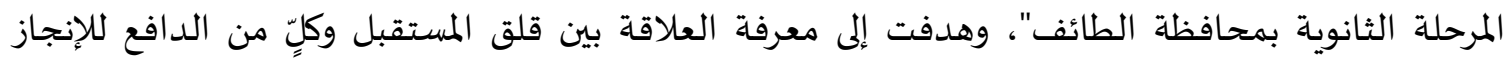

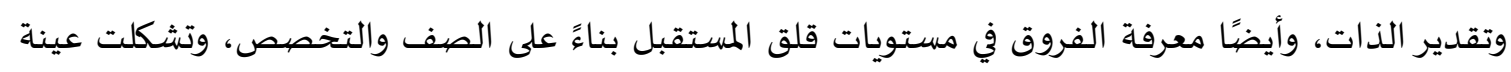

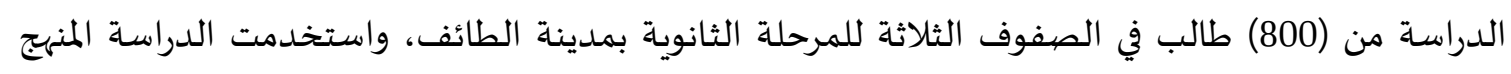
الوصفي، كما تم استخدام مقياس قلق المستقبل (المشيني، 2009)، ومقياس دافعية الإنجاز (الغامدي،

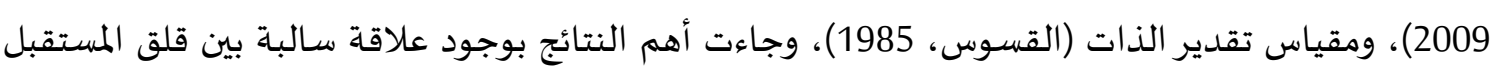

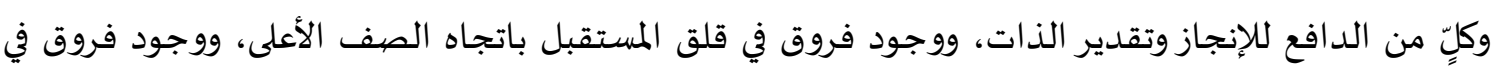

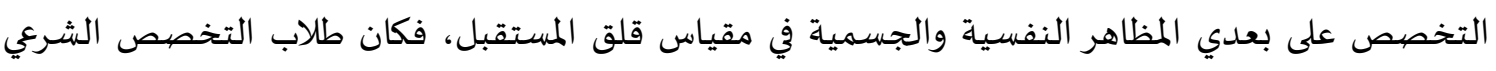
أكثرشعورًا بالقلق من طلاب التخصص بعل الطبيعي.

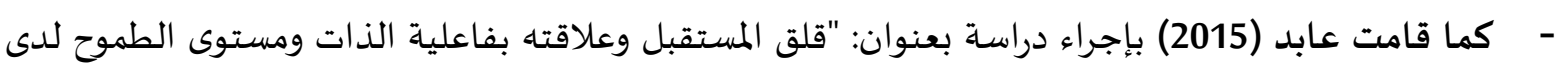

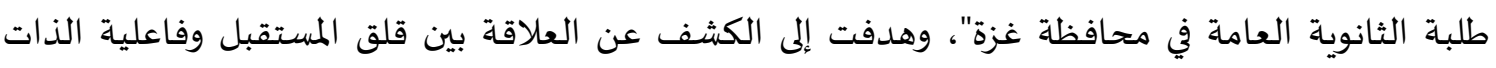

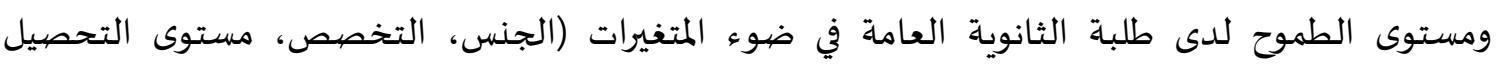

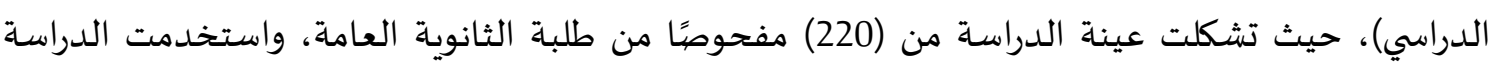

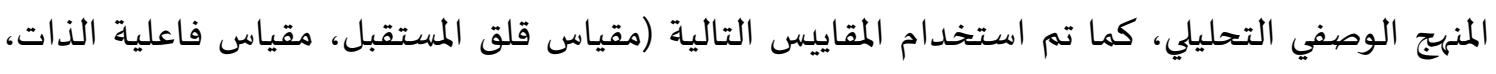

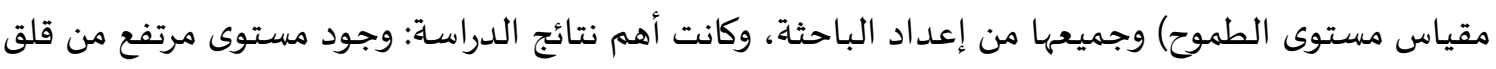

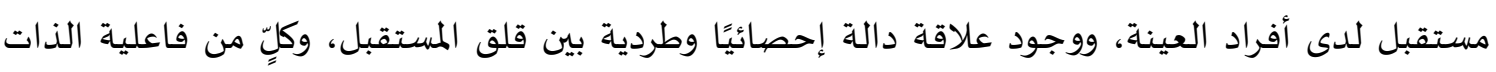

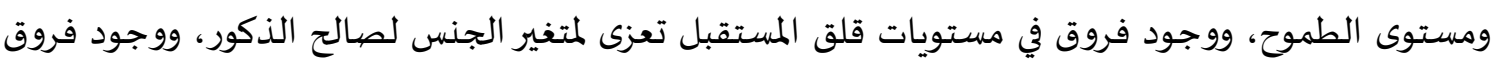

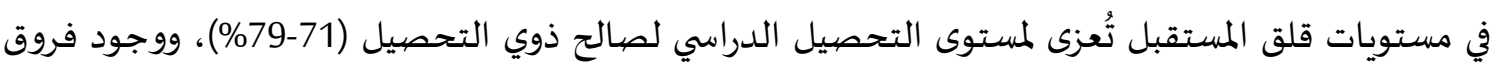

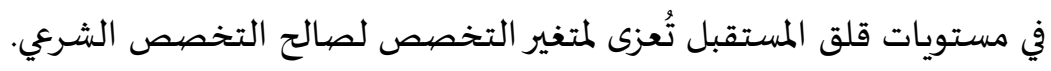


- وأجرى العتيبي (2016) دراسة بعنوان: "أثر قلق المستقبل على التحصيل الدراسي لدى طلاب المرحلة

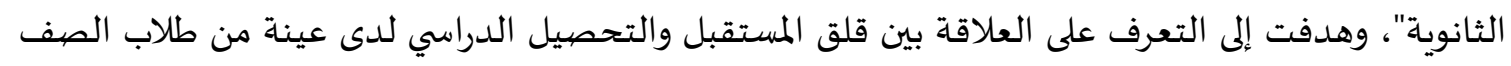

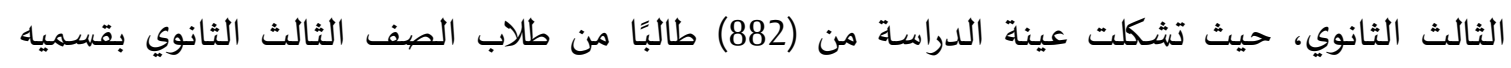

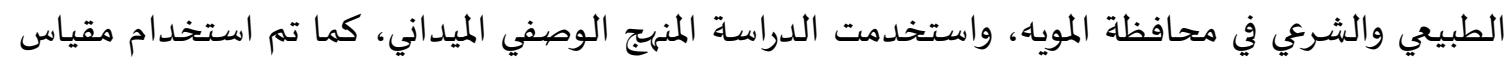
قلق المستقبل (المشيخي، 2009)، واستمارة المستوى الاجتماعي والاقتصادي (إعداد الباحث)، وكانت أهم نتائج

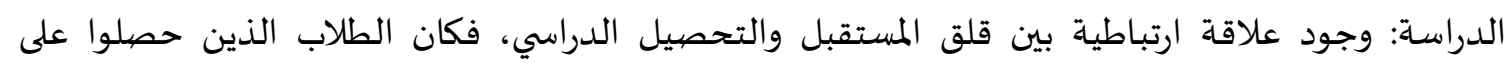

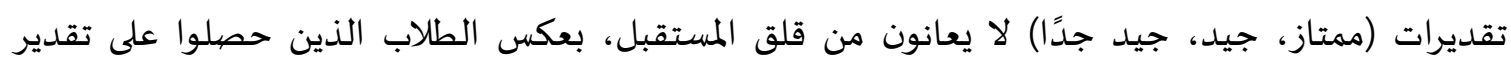

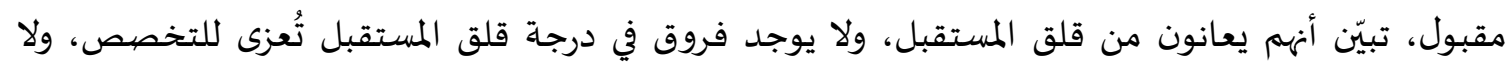

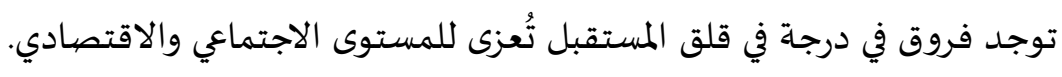

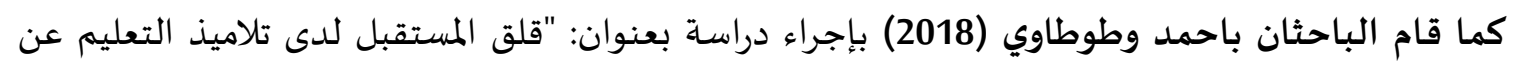

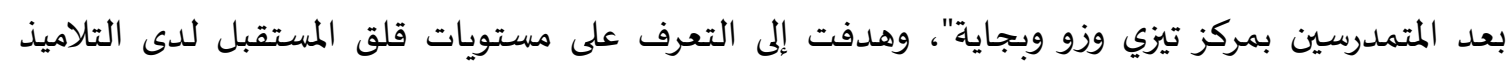

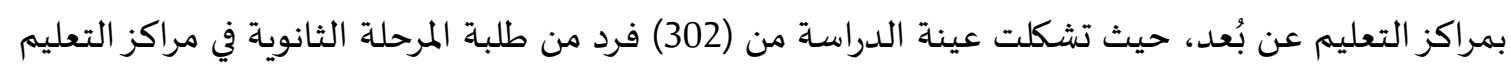

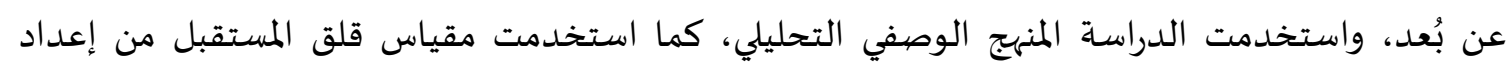

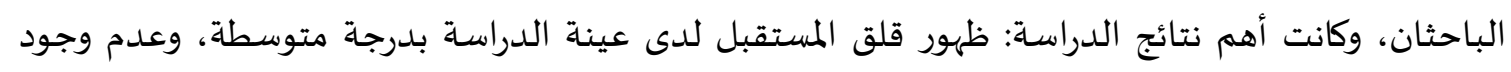
فروق في درجة قلق المستقبل تعزى لمتغير الجنس. وأجرت الخطاف (2021) دراسة بعنوان: "قلق المستقبل لدى عينة من طالبات المرحلة الثانوية في بريدة"،

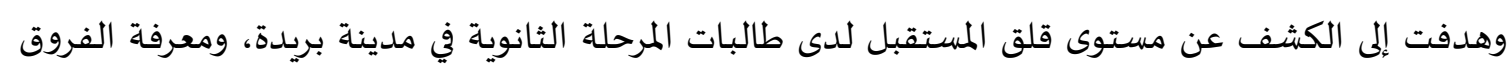

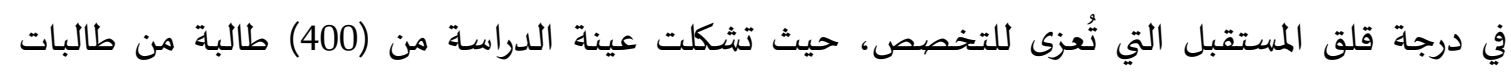
المرحلة الثانوية، واستخدمت الدراسة المنهج الوصفي، كما استخدمت مقياس قلق المقائل المستقبل (شقير، 2005)،

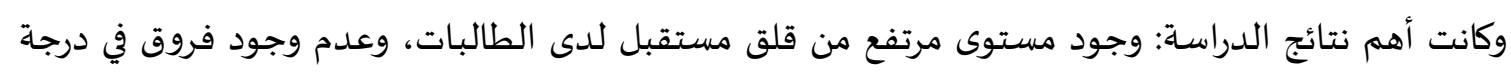
قلق المستقبل تُعزى للتخصص. دراسات سابقة تناولت قلق المستقبل وعلاقته بالأزمات:

أجرى العوبلي (2018) دراسة بعنوان: "قلق المستقبل لدى طلبة الجامعة وعلاقته بالصلابة النفسية أثناء

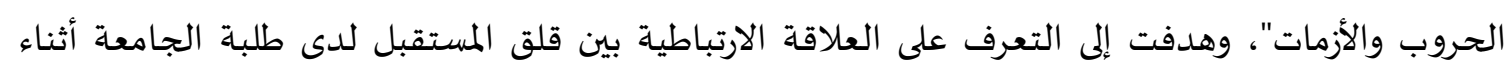

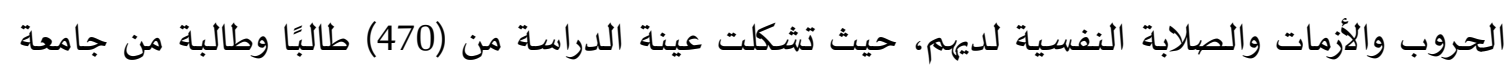

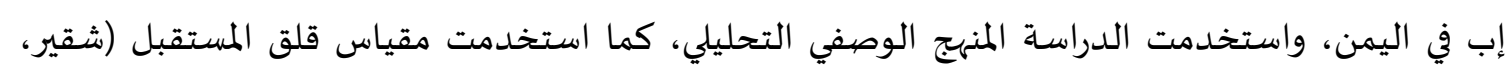

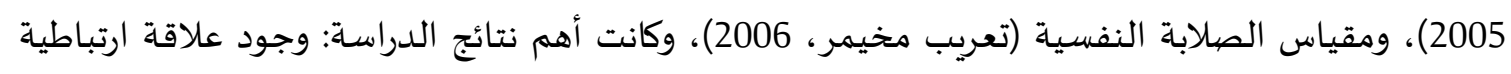

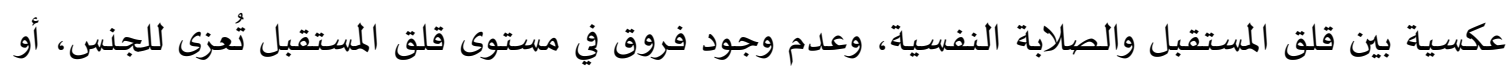
الكلية، أو المستوى الدراسي. بين فلميت

خلاصة الدراسات السابقة والتعقيب عليها:

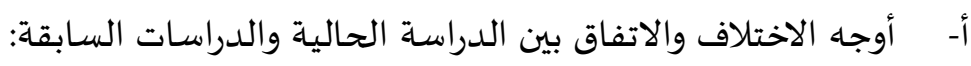

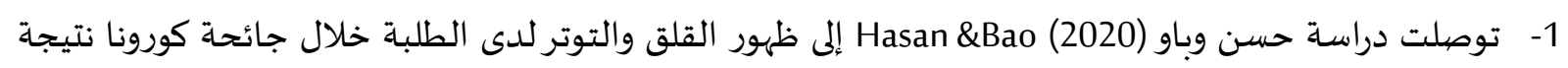

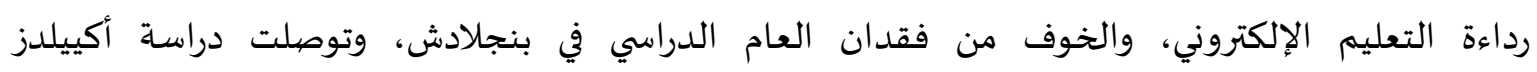

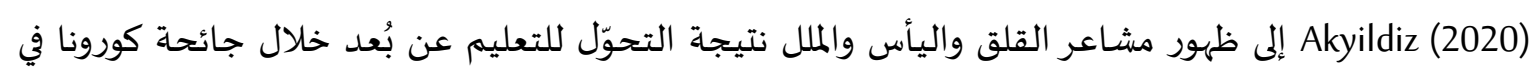


تركيا، ووجدت دراسة الرفاعي (2020) مستوى مرتفع من قلق المستقبل لدى الطلبة في لبنان، وجميعها أجريت

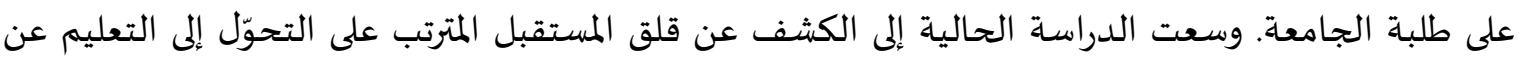
بُعد أثناء جائحة كورونا لدى طلبة المعاه وسعت المرحلة الثانوية.

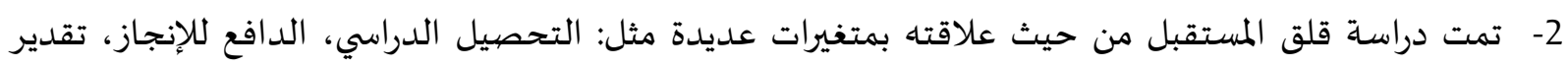

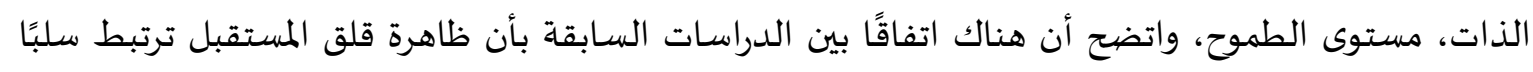

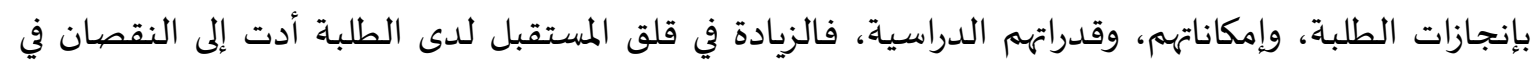

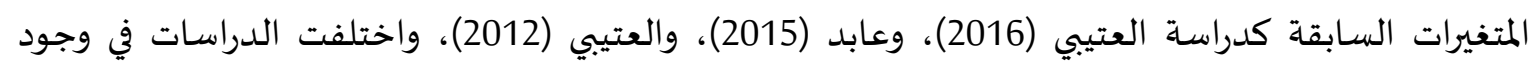

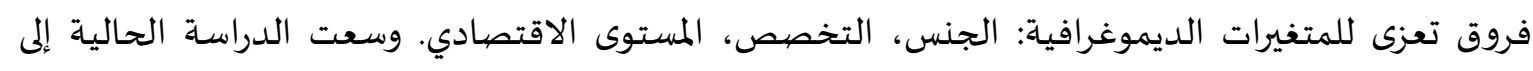

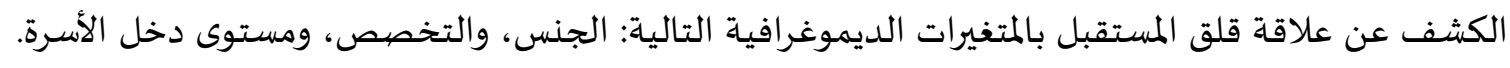
3- توصلت دراسة الخطاف (2021) إلى وجود مستوى مرتفع من قلق المستقبل لدى طالبة البات المرحلة الثانوية في

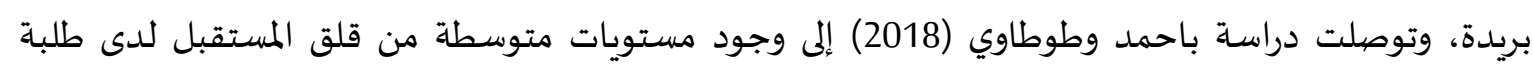

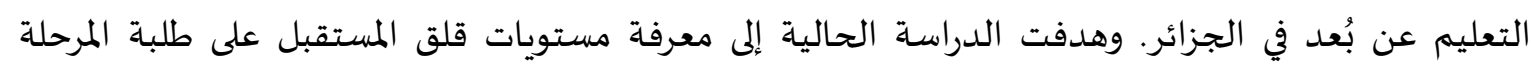
الثانوية في المدينة المنورة. 4- وجدت دراسة العوبلي (2018) علاقة ارتباطية عكسية بين قلق المستقبل والصلابة النفسية أثناء الأزمات والحروب. وتوجهت الدراسة الحالية إلى دراسـة قلق المستقبل في ظل أزبة أزمة جائحة كورونا.

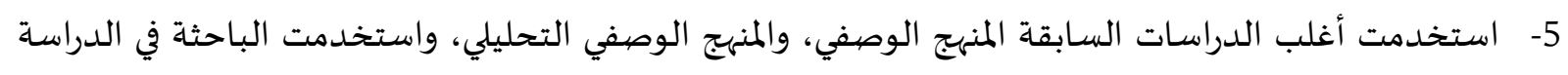

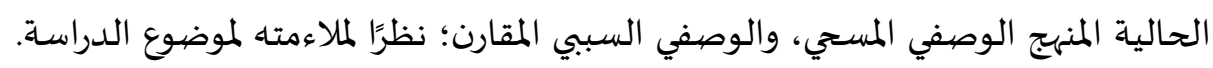

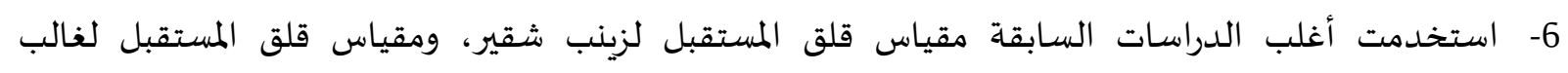

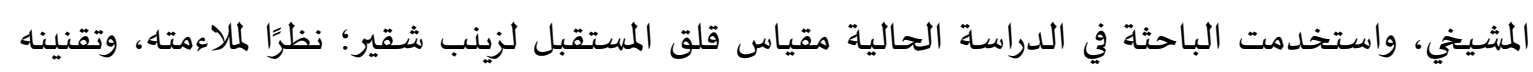
على البيئة السعودية. ب- أوجاه الاستفادة من الدراسات السابقة: السعودية.

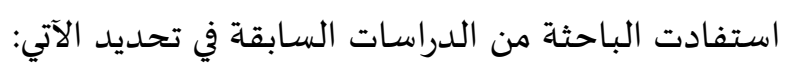

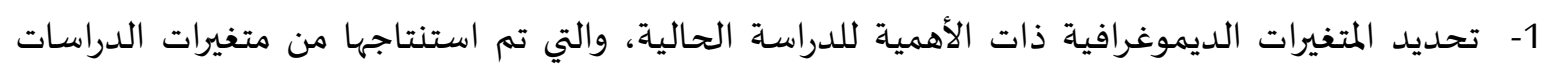

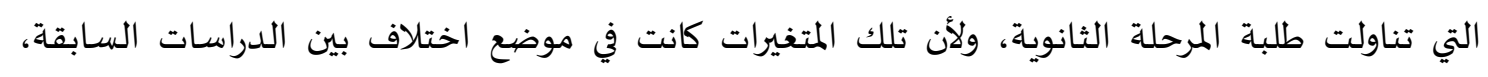
حاولت الدراسة الحالية الكشف عن تأثيرها في متغير قلق المستقبل.

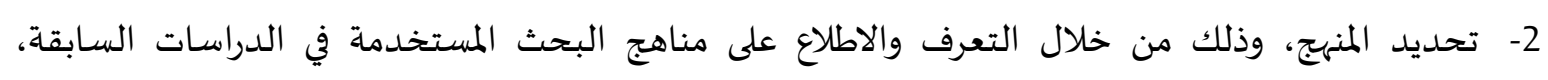
واختيار أكثر المناهج ملاءمة للدراسة الحالية. 3- تحديد الأداة، وتم ذلك من خلال استعراض أدوات البحث المتارة المستخدمة في الدراسـات السابقة، واختيار الأداة

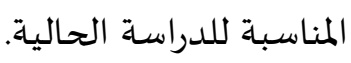


استخدمت الباحثة في هذه الدراسة المنهج الوصفي التحليلي؛ لمعرفة مستويات قلق المستقبل لدى أفراد

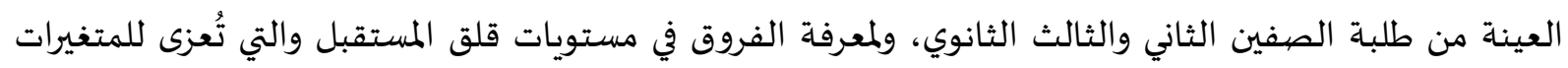

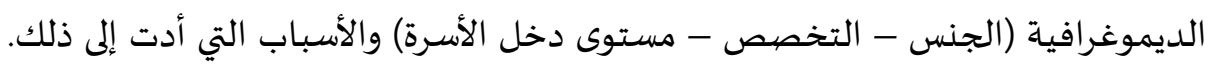

\section{مجتمع الدراسـة:}

يتألف مجتمع الدراسة الحالية من جميع طلاب وطالبات المرحلة الثانوية بالصفين الثاني والثالث الثانوي

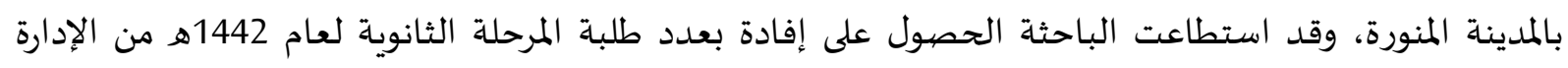
العامة للتعليم في منطقة المدينة المنورة، حيث بلغ عدد الطلبة (54638) طالبًا وطالبة.

عينة الدراسـة:

تألفت عينة الدراسـة من:

1 - 1 - عينة الدراسة الاستطلاعية:

وهم الطلبة الذين تم اختيارهم بطريقة عشوائية من طلبة المرحلة الثانوية بالصفين (الثاني، والثالث)

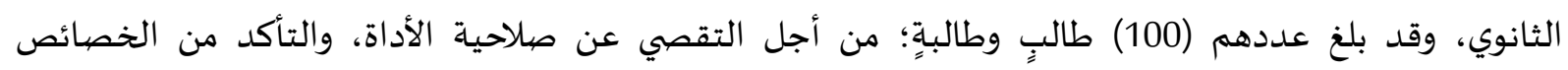

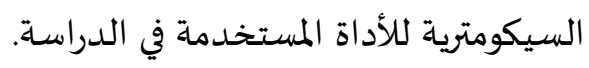

2- 2 ت عينة الدراسة الأساسية:

تشكلت عينة الدراسة الأولية من (548) طالبًا وطالبة في المرحلة الثانوية، وبعد تنقيح العينة واستبعاد كلًا

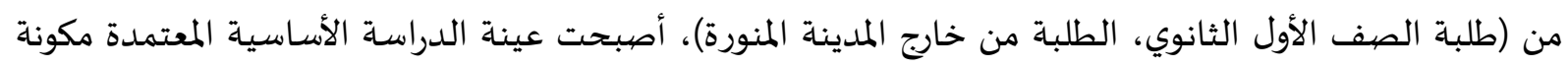

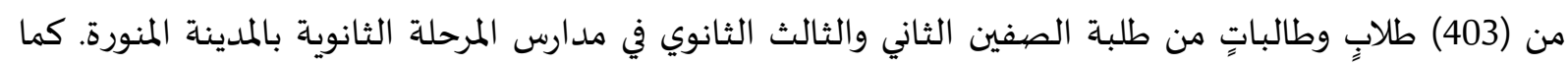
هو موضح بالجدول التالي:

جدول (1) عدد ونسبة أفراد العينة حسب المتغيرات الديموغرافية

\begin{tabular}{|c|c|c|c|}
\hline النسبة المئوية & العدد & الفئات & المتغير \\
\hline $92.1 \%$ & 371 & أنثى & \multirow{2}{*}{ 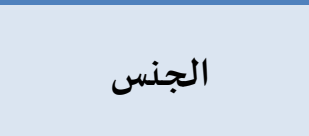 } \\
\hline $7.9 \%$ & 32 & ذكر & \\
\hline $51.6 \%$ & 208 & 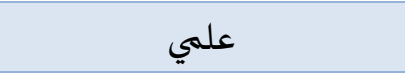 & \multirow{2}{*}{ التخصص } \\
\hline $48.4 \%$ & 195 & أدبي & \\
\hline $29.8 \%$ & 120 & أقل من ... .0 شهرياً & \multirow{3}{*}{ مستوى دخل الأسرة } \\
\hline $43.7 \%$ & 176 & من . . . إلى . . 10 شهرياً & \\
\hline $26.6 \%$ & 107 & أكثر من .. . 10 شهرياً & \\
\hline
\end{tabular}

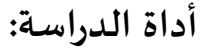

مقياس قلق المستقبل (شقير، 2005): 
استخدمت الباحثة المقياس الذي أعدته (شقير، 2005) كما ورد في دراسة (العنزي، 2010) المقننة والمطبقة على البيئة السعودية. وفيما يلي توصيف المقياس:

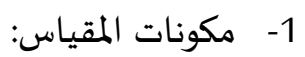

هو عبارة عن مقياس متدرج كالتالي: معترض بشدة (لا)، معترض أحيانًا (قليلًا)، بدرجة متوسطة، عادةً (كثيرًا)، دائمًا (تمامًا). وأمام كل فقرة الدرجات التالية: (4-2-2-0) وذلك عندما يكون اتجاه العبارات نحو قلق

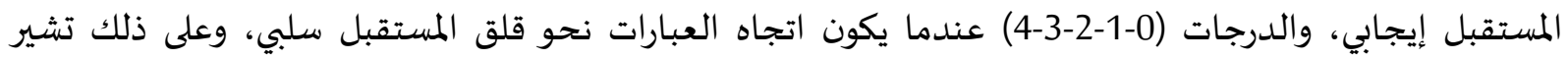
الدرجة المرتفعة في نتائج المقياس إلى ارتفاع قلق المستقبل لدى المئ الفرد. ويتكون المقياس من (28) عبارة تم توزيعها على (5) أبعاد كما في الجدول التالي:

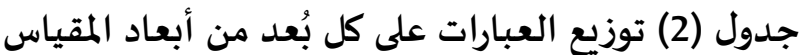

\begin{tabular}{|c|c|c|}
\hline العبارات التابعة للبُعد & 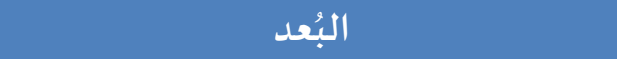 & h \\
\hline $24-22-21-20-17$ & القلق المتعلق بالمشكلات الحياتية المستقبلية & 1 \\
\hline $26-25-19-18-10$ & قلق الصحة وقلق الموت & 2 \\
\hline $28-23-14-13-11-6-3$ & القلق الذهني (قلق التفكير في المستقبل) & 3 \\
\hline $16-12-9-8-7-4$ & اليأس من المستقبل المبل & 4 \\
\hline $27-15-5-2-1$ & الخوف والقلق من الفشل في المستقبل & 5 \\
\hline
\end{tabular}

تتراوح الدرجة الكلية للمقياس من (صفر) إلى (112) درجة، وتحدد مستويات قلق المستقبل طبقًا للجدول

\section{جدول (3) توزيع اتجاهات المقياس ومستويات القلق حسب الدرجة}

\begin{tabular}{|c|c|c|c|}
\hline \multicolumn{2}{|c|}{ اتجاه قلق المستقبل } & اتجاه التصعيح & 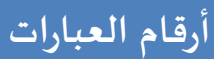 \\
\hline من 91 إلى 112 درجة & قلق مستقبل مرتفع جدًا (شديد) & \multirow{2}{*}{$0-1-2-3-4$} & \multirow{2}{*}{ من 1 إلى 10} \\
\hline من 68 إلى 90 درجـة & قلق مستقبل مرتفع & & \\
\hline من 45 إلى 67 درجة & قلق مستقبل معتدل (متوسط) & \multirow{4}{*}{$4-3-2-1-0$} & \multirow{4}{*}{ من 11 إلى 28} \\
\hline من 22 إلى 44 درجـة & قلق مستقبل بسيط & & \\
\hline من صفر إلى 21 درجة & قلق مستقبل منخفض & & \\
\hline من صفر إلى 112 درجة & الدرجة الكلية لقلق المستقبل & & \\
\hline
\end{tabular}

3- تقنين المقياس:

أ- صدق المقياس: قامت (شقير، 2005) باختبار صدق المقياس بالطرق التالية: (الصددق الظاهري، صدق

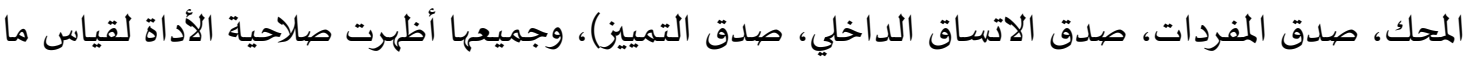
وضعت لأجله، حيث دلت على ذلك آراء المحكمين، وقيم معاملات الارتباط.

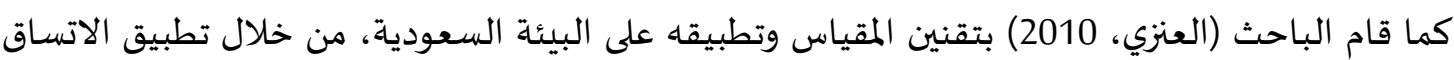

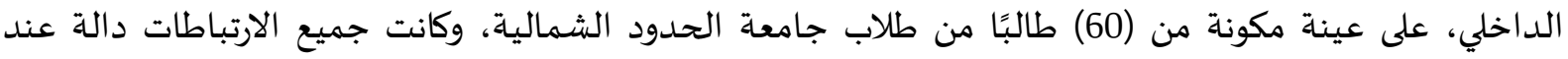
(0.01)، و) و(0.01). 
ب- ثبات المقياس: قامت (شقير، 2005) باختبار ثبات المقياس بالطرق التالية: (طريقة إعادة الاختبار، طريقة

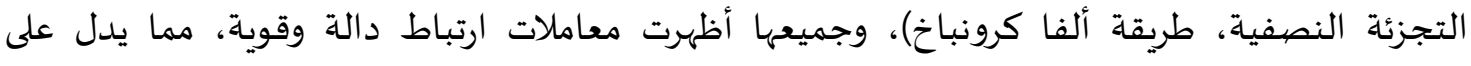
صلاحية استخدام المقياس. كما قام الباحث (العنزي، 2010) باختبار ثبات المقياس بالطرق المقاسية التالية: (التجزئة النصفية، ألفا كرونباخ)، وجميعها أظهرت معاملات ارتباط دالة، وهذا يؤكد صلاحية المقياس.

4- التحقق من صبدق وثبات المقياس في الدراسة الحالية:

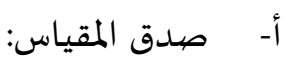

قامت الباحثة بإعداد دراسة استطلاعية لأداة الدراسة الحالية، وذلك من خلال تطبيقها على عينة من

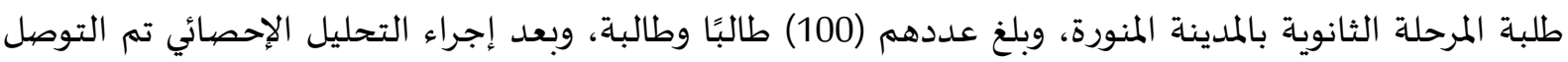
الاتساق الداخلي لعبارات أبعاد المقياس:

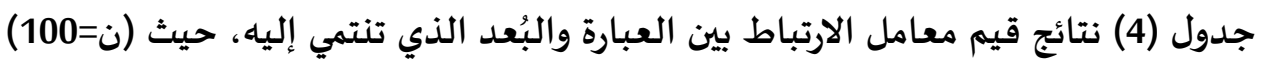

\section{معامل الاتساق}

الداخلي (معامل

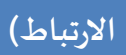

$.720 * *$

$.669^{* *}$

1- أشعر بالانزعاج لاحتمال وقوع كارثة قريباً بسبب كثرة الحوادث هذه الأيام.

$.718^{* *}$

$.634^{* *}$

$.501^{* *}$

$.549 * *$

$.567^{* *}$

$.752^{* *}$

$.777^{* *}$

2- الحياة المملوءة بالعنف والإجرام تجعل الفرد يتوقع الخطر لنفسسه في أي وقت.

3- كثرة البطالة في المجتمع يهدد بحياة صعبة وسوء التوافق الزواجي مستقبلاً.

4- غلاء المعيشة وانخفاض الدخل وانخفاض العائد المادي يقلقني على مستقبلي.

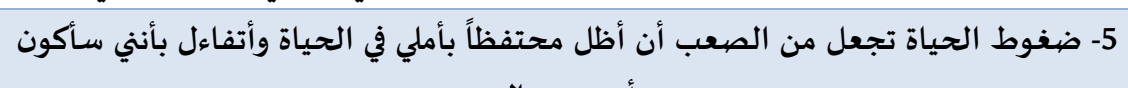

$$
\text { بأحسن حال. }
$$

1- حياتي مملوءة بالحيوية والنشاط والرغبة في تحقيق الآمال.

2- أشعر بتغيرات مستمرة في مظهري (شكلي) تجعلني أخاف أن أكون غير جذاب (لا يتقبلني)

$$
\text { أمام الآخرين مستقبلاً. }
$$

3- ينتابني شعور بالخوف والوهم من اصابتي بمرض خطير (أو حادث) في أي وقت.

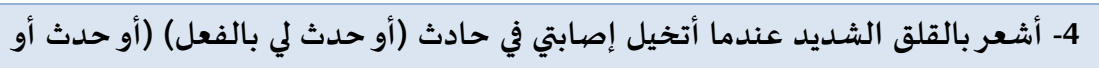

يحدث لشخص يهمني).

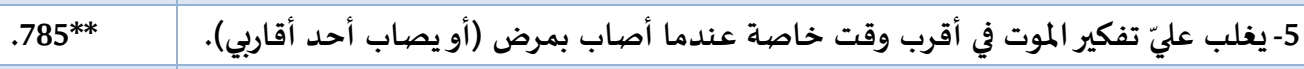

1- تراودني فكرة أنني قد أصبح شخصياً عظيماً في المستقبل.

2- 20 الأفضل أن تعمل لدنياك كأنك تعيش أبداً، وتعمل لآخرتك كأنك تموت غداً.

3- يمتلكني الخوف والقلق والحيرة عندما أفكر في المستقبل وأنه لا حول لي ولا قوة في ت

$$
\text { المستقبل. }
$$

$.380^{* *}$

4- أنا من الذين يؤمنون بالحظ، ويتحركون على أسـاسه.

$.582^{* *}$

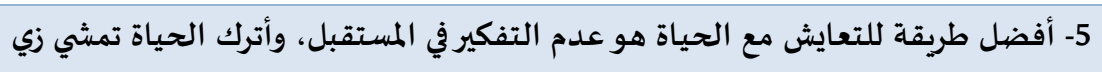

ما تمشي.

$.619^{* *}$

6- المستقبل غامض ومبهم (مجهول) لدرجة تجعل من الصعب (من العبث) أن يرسم

الشخص أي خطة للأمور الهامة في مستقبله.

$.505^{* *}$
7- أشعر أن الحياة عقيمة بلا هدف ولا معنى ولا مستقبل واضح.
البُعد الأول:

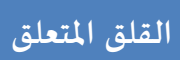

بالمشكلات المقات المقات

الحياتية

المستقبلية الحياتية

عبارات البُعد

الثاني:

قلق الصحة

وقلق الموت

عبارات البُعد

الثالث: - الثبارت

القلق الذهني 


\begin{tabular}{|c|c|c|}
\hline $.666^{* *}$ & 1- عندي طموحات وأهداف واضحة في الحياة، وأعمل لمستقبلي وفق خطة رسمتها لنفسي & \multirow{6}{*}{ اليأس الرابع: المبتعد } \\
\hline $.696^{* *}$ & 2- أشعر أن الغد (المستقبل) سيكون يوماً ما مشرقاً، وستتحقق آمالي في الحياة. & \\
\hline $.744^{* *}$ & 3- أملي في الحياة كبير، لأن طول العمر يُبلغ الأمل. & \\
\hline $.722^{* *}$ & 4- يخبئ الزمن مفاجآت سارّة، ولا يأس في الحياة ولا حياة مع اليأس. & \\
\hline $.471^{* *}$ & 5- يدفعني الفشل إلى اليأس وفقدان الأمل في تحقيق مستقبل أفضل. & \\
\hline $.570^{* *}$ & 6- أشعر بالفراغ واليأس وفقدان الأمل في الحياة، وأنه من الصعب امكانية تحسنها مستقبلاً. & \\
\hline $.590^{* *}$ & 1- أؤمن بالقضشاء والقدر، وأن القدر يحمل أخباراً سارّة في المستقبل. & \multirow{5}{*}{ الخبارات البُعد } \\
\hline $.423^{* *}$ & 2- التفوق يدفعني دائماً لمزيد من التفوق، وأكافح لتحقيق مستقبل باهر. & \\
\hline $.601^{* *}$ & 3- الالتزام الديني والأخلاقي والتمسك بمبادئ معينة يضمن للإنسان مستقبل آمن. & \\
\hline $.612^{* *}$ & 4- تمضي الحياة بشكل مزيف ومحزن ومخيف مما يجعلني أقلق وأخاف من المجهول. & \\
\hline $.684^{* *}$ & 5- أنا غير راضٍ عن مستوى معيشتي بوجه عام مما يشعرني بالفشل في المستقبل. & \\
\hline
\end{tabular}

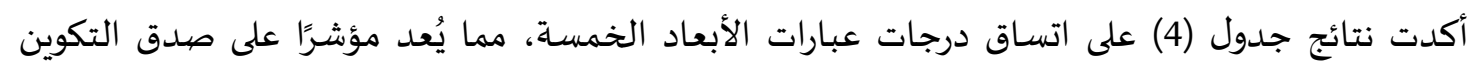

$$
\text { ب- الفرضي لجميع الأبعاد. }
$$

قامت الباحثة باستخدام طريقة معاملات ألفا كرونباخ لكل أبعاد المقياس.

\begin{tabular}{|c|c|c|c|}
\hline مؤشر الصيدق & كعامل ألفا & المناصر & 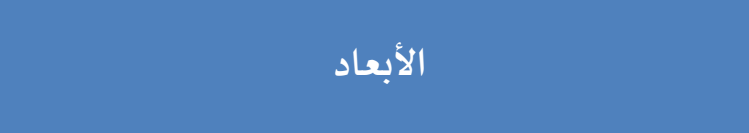 \\
\hline $80.93 \%$ & 0.655 & 5 & البُعد الأول: القلق المتعلق بالمشكلات الحياتية \\
\hline $85.15 \%$ & 0.725 & 5 & البُعد الثاني: قلق الصحة وقلق الموت \\
\hline $70.07 \%$ & 0.491 & 7 & البُعد الثالث: القلق الذهني \\
\hline $84.44 \%$ & 0.713 & 6 & البُعد الرابع: اليأس من المستقبل \\
\hline $71.69 \%$ & 0.514 & 5 & البُعد الخامس: الخوف والقلق من الفشل في المستقبل \\
\hline $93.75 \%$ & 0.879 & 28 & مقياس قلق المستقبل \\
\hline
\end{tabular}

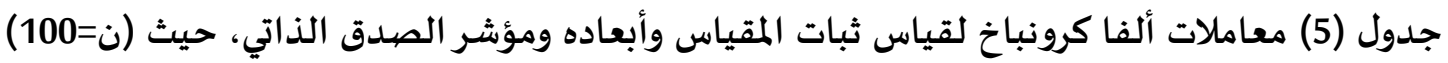

$$
\text { يتضح من جدول (5) مايلي: }
$$

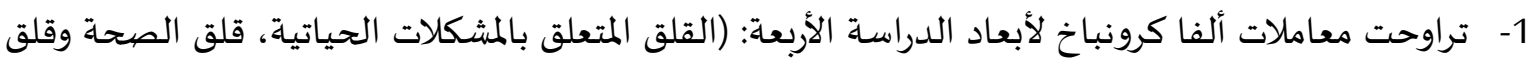

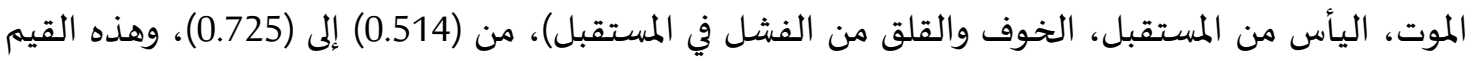

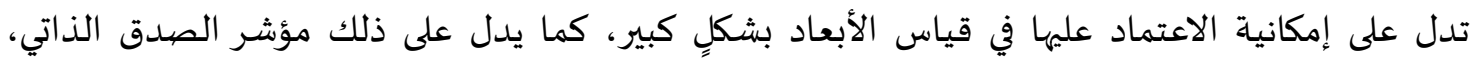

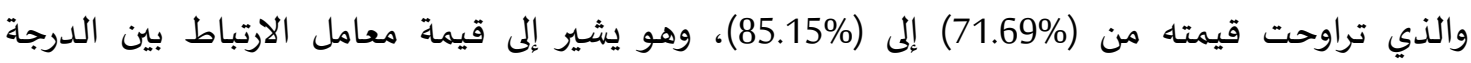
الحقيقية للمقياس والدرجة المُشَاهدة.

2- يُلاحظ انخفاض قيمة معامل ثبات البُعد الثالث (القلق الذهني) حيث بلغ معامل ألفا كرونباخ (0.491)، إلا

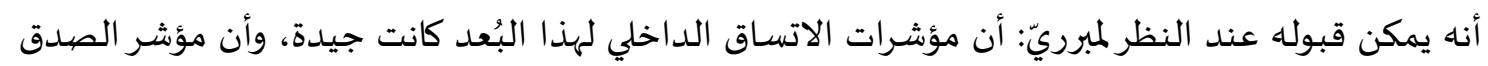


الذاتي بلغ (70\%)، وهذا يعني أن البُعد الثالث يستطيع استخلاص (70\%) من الدرجة الحقيقية المُعبرة عن

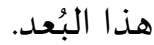
3- بالنسبة للمقياس ككل فإن معامل ألفا كرونباخ بلغ (0.879)، أي أن نتائج عبارات مقياس قلق المستقبل

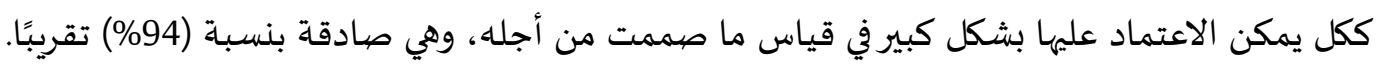

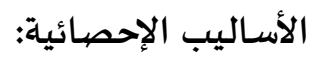
للإجابة علن أسئلة الدراسة قامت الباحثة بمعالجة البيانات إحصيائيًا بواسطة حزمة البيانات (برنامج SPSS

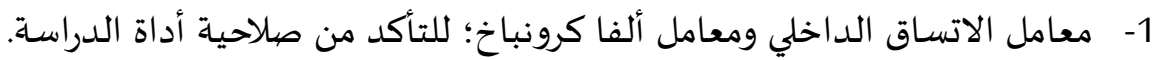
2- اختبار كولومجروف سيمرنوف؛ لمعرفة تبعية متغير قلق المستقبل للتوزيع الطبيعي.

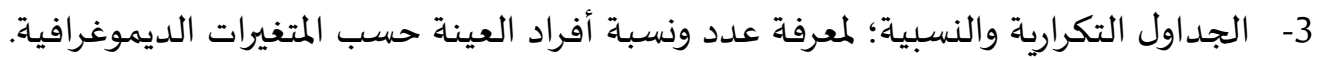

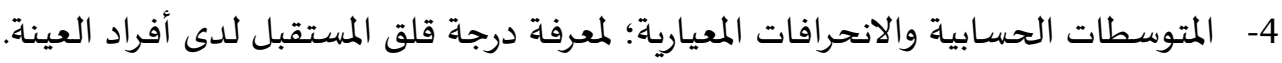

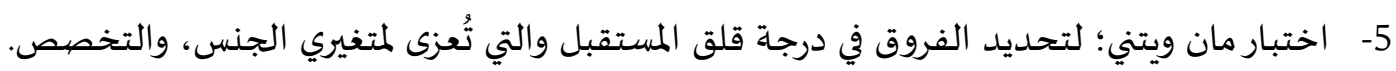
6- اختبار كروسكال - ويلز؛ لمعرفة الفروق في درجة قلق المستقبل والتي تُعزى لمتغير مستوى دخل الأسرة.

4- - نتائج الدراسـة ومناقشتها.

نتيجة السؤال الأول: "ما درجة قلق المستقبل في ضوء التحول إلى التعليم عن بُعد أثناء جائحة كورونا

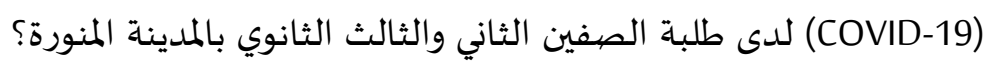

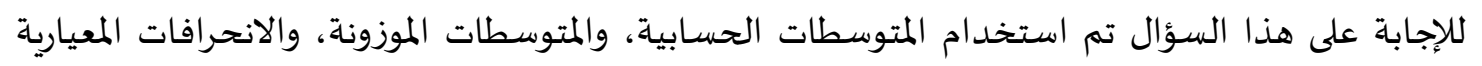
لأبعاد المقياس، وكانت النتائج كما في الجدول التالي:

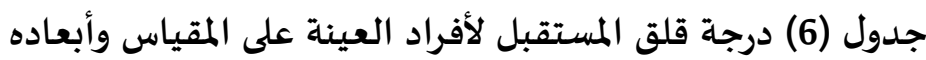

\begin{tabular}{|c|c|c|c|c|c|c|}
\hline دالمستة قلق المبل & المتوسط الموزون & العبارات & الانحراف & المتوسط الحسابي & العينة & البُعد \\
\hline متوسط & 48.57 & 5 & 4.42369 & 8.6725 & 403 & القلق المتعلق بالمشكلات الحياتية \\
\hline بسيط & 36.18 & 5 & 4.30323 & 6.4615 & 403 & قلق الصحة وقلق الموت \\
\hline بسيط & 31.80 & 7 & 4.34031 & 7.9504 & 403 & القلق الذهني \\
\hline بسيط & 28.22 & 6 & 4.30611 & 6.0471 & 403 & اليأس من المستقبل \\
\hline منخفض & 20.45 & 5 & 3.22743 & 3.6526 & 403 & الخوف والقلق من الفشل في \\
\hline بسيط & 32.78 & 28 & 16.84183 & 32.7841 & 403 & قلق المستقبل \\
\hline
\end{tabular}

اتضح من جدول (6) أن: 
1- بلغ المتوسط الموزون لبُعد القلق المتعلق بالمشكلات الحياتية المستقبلية (48.57)، مما يعني أنه يقع بالفئة الثالثة على درجات مقياس قلق المستقبل، من (45 - 67) درجة، وهي تعبر عن وجود درجة معتدلة أو متوسطة المباتها

$$
\text { من قلق المستقبل. }
$$

2- بلغ المتوسط الموزون لبُعد قلق الصحة وقلق المبلق الموت (36.18)، ولبُعد القلق الذهني (31.80)، ولبُعد اليأس

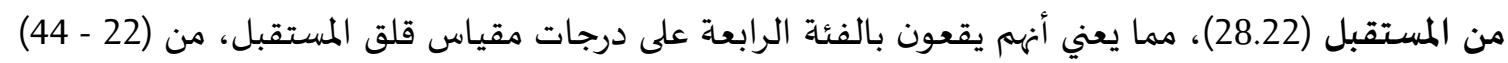

$$
\text { درجاة، وهي تعبر عن وجود درجة بسيطة من قلق المستقبل. }
$$

3- بلغ المتوسط الموزون لبعد الخوف والقلق من الفشل في المستقبل (20.45)، مما يعني أنه يقع بالفئة

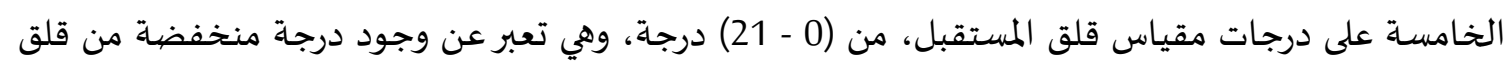

$$
\text { المستقبل. }
$$

4- أما بالنسبة للمتوسط الموزون لمقياس قلق المستقبل بشكلٍ عام، قد بلغ (32.78)، مما يعني أنه يقع بالفئة

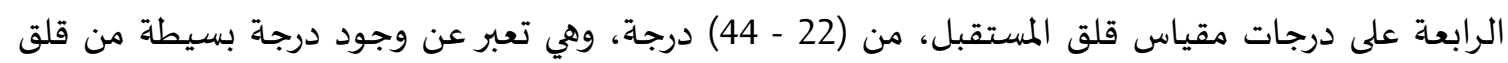

$$
\text { المستقبل. }
$$

كما يوضح جدول (6) أن بُعد القلق المتعلق بالمشكلات الحياتية المستقبلية حظي بمستوى القلق المعتدل

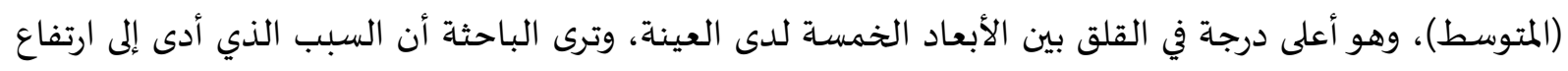

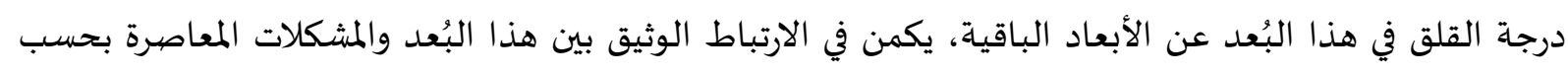

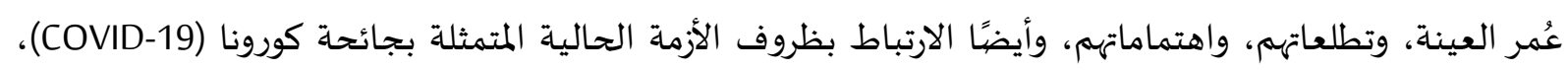

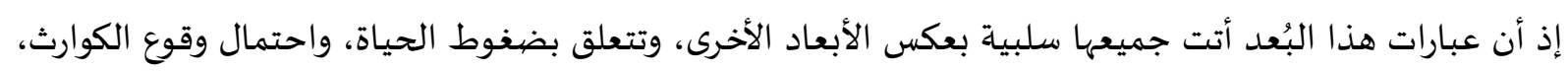

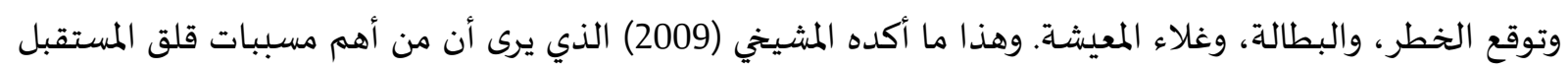

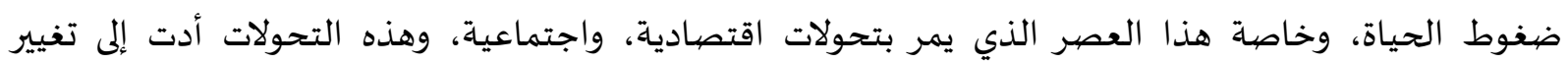

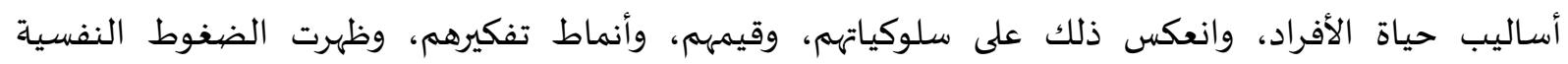

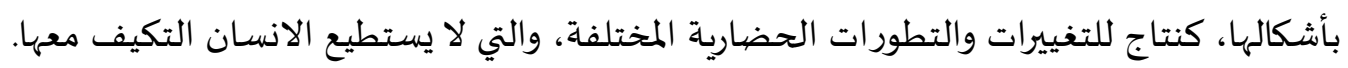

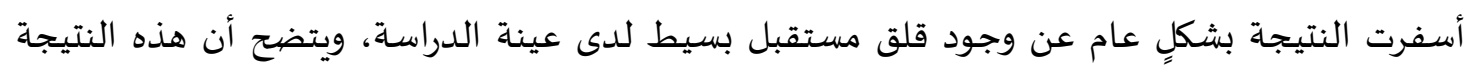

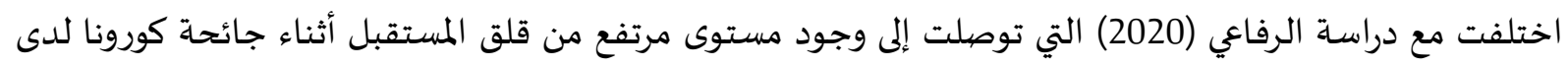

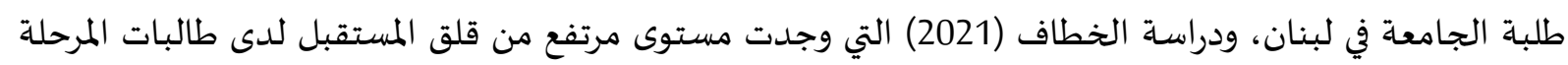

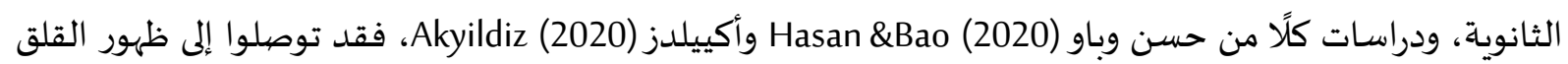

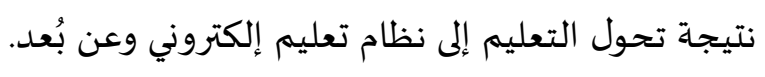

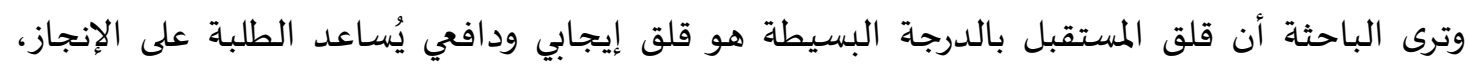

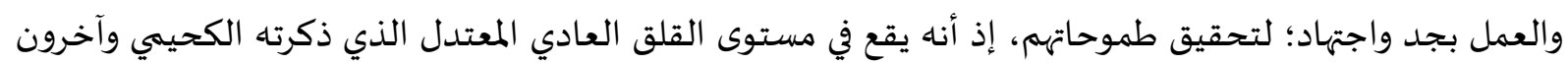

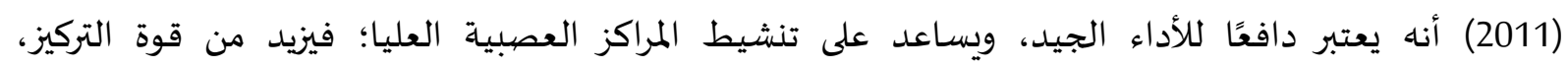

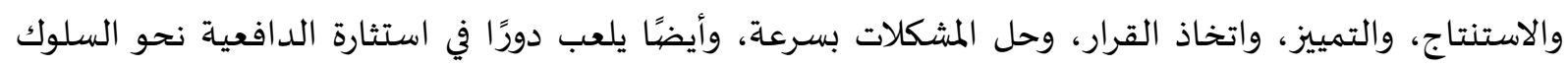

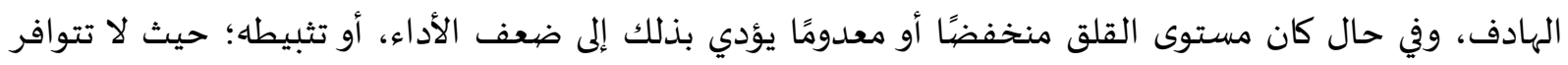

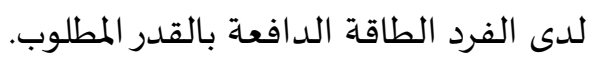
كما تعزو الباحثة درجة قلق المستقبل البسيطة لدى طلبة المرحلة الثانوية بالصفين (الثاني والثالث) في ضوء التحوّل إلى التعليم عن بعد أثناء جائحة كورونا (COVID-19) بالمدينة المنورة للأسباب التالية: 
1- جهود المملكة العربية السعودية في الاستعداد والتنظيم للقطاع التعليميّ بما يخدم الطلبة من النواحي

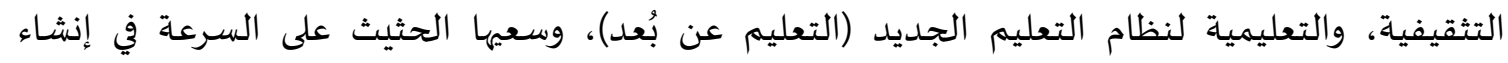

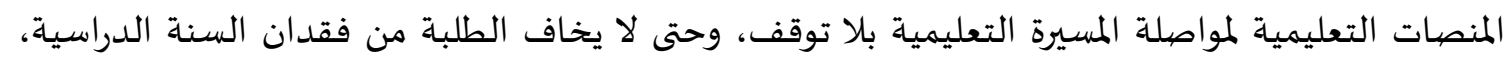

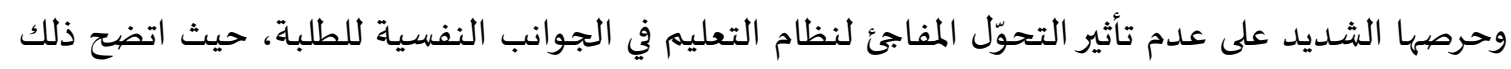

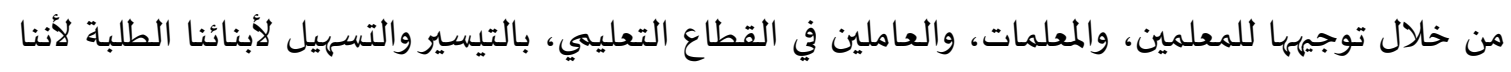

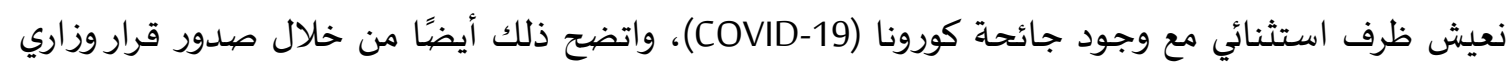

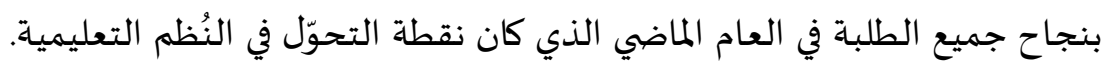

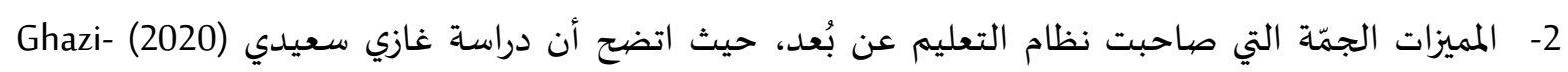

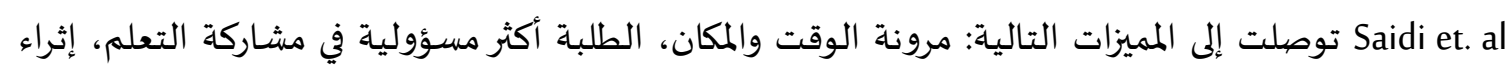

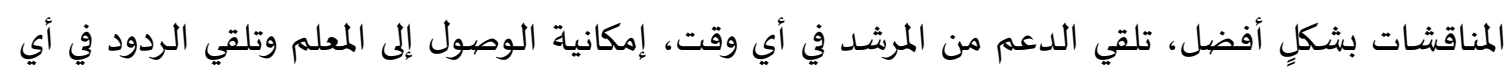

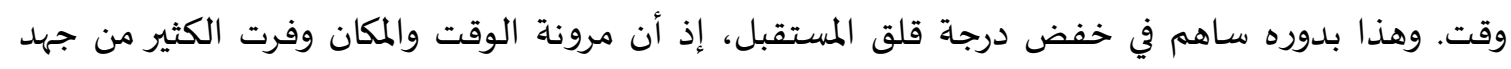

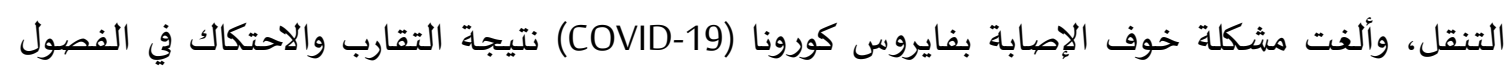

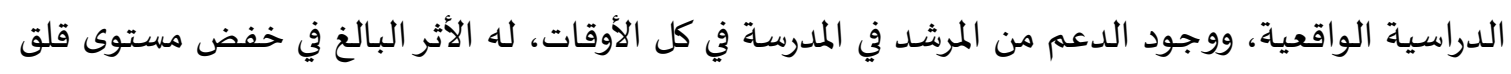

المستقبل. 3- حقق نظام التعليم عن بُعد عدة فوائد، لبعض فئات المجتمع. حيث ذكر عامر (2018) أن نظام التعليم عن

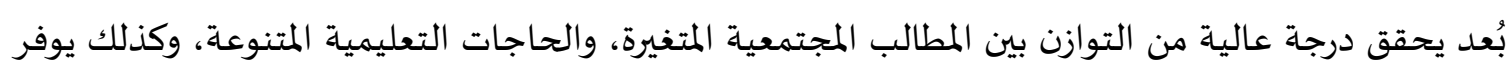

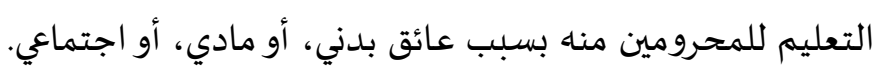

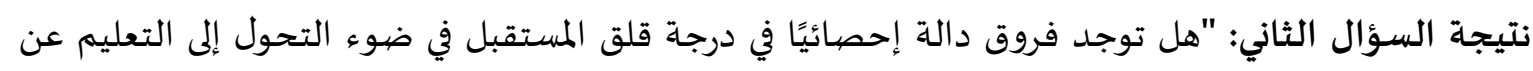

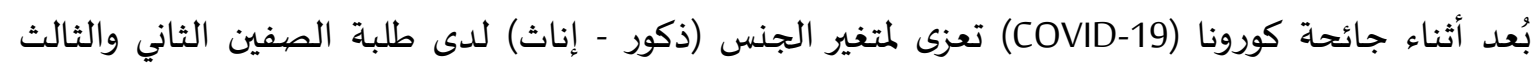

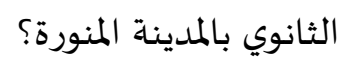

للإجابة على هذا السؤال تم التحقق من تبعية متغير قلق المستقبل للتوزيع الطبيعي باستخدام اختبار

$$
\text { كولومجروف سيمرنوف وكانت النتائج كالتالي: }
$$

جدول (7) نتائج اختبار تبعية متغير قلق المستقبل للتوزيع الطبيعي

\begin{tabular}{|c|c|c|}
\hline \multicolumn{2}{|c|}{ كولومجروف سيمنروف } & \multirow{2}{*}{ الأبعاد/ المتخير } \\
\hline مستوى الدلالة ل & القيمة الإحصيائية & \\
\hline 0.000 & 0.067 & القلق المتعلق بالمشكلات الحياتية \\
\hline 0.000 & 0.116 & قلق الصحة وقلق الموت \\
\hline 0.000 & 0.080 & القلق الذهني الذي \\
\hline 0.000 & 0.095 & اليأس من المستقبل \\
\hline 0.000 & 0.186 & الخوف والقلق من الفشل في المستقبل \\
\hline 0.000 & 0.078 & متغير قلق المستقبل \\
\hline
\end{tabular}

يتضح من جدول (7) أن مستوى الدلالة للمقياس وأبعاده (0.000) وهي أقل من (0.05)، مما يعني عدم المبر

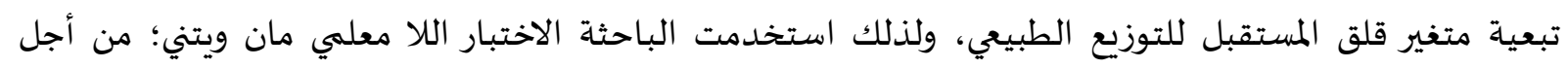

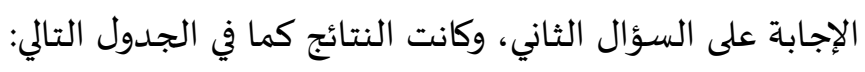




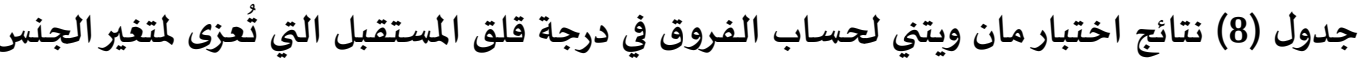

\begin{tabular}{|c|c|c|c|c|c|}
\hline المعنوية & قيمة مان ويتني & حجم العينة & متوسط الرتب & 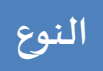 & 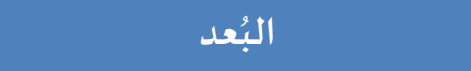 \\
\hline \multirow{2}{*}{0.438} & \multirow{2}{*}{5447.000} & 371 & 203.32 & أنثى & \multirow{2}{*}{ القلق المتعلق بالمشكلات الحياتية } \\
\hline & & 32 & 186.72 & 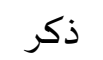 & \\
\hline \multirow{2}{*}{0.541} & \multirow{2}{*}{5551.000} & 371 & 203.04 & أنثى أنى & \multirow{2}{*}{ قلق الصحة وقلق الموت } \\
\hline & & 32 & 189.97 & ذ كر & \\
\hline \multirow{2}{*}{0.689} & \multirow{2}{*}{5683.500} & 371 & 201.32 & أنثى & \multirow{2}{*}{ القلق الذهني } \\
\hline & & 32 & 209.89 & 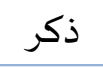 & \\
\hline \multirow{2}{*}{0.959} & \multirow{2}{*}{5903.500} & 371 & 201.91 & أنثى أن & \multirow{2}{*}{ اليأس من المستقبل } \\
\hline & & 32 & 203.02 & 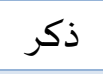 & \\
\hline \multirow{2}{*}{0.704} & \multirow{2}{*}{5697.500} & 371 & 201.36 & أنثى & \multirow{2}{*}{ الخوف والقلق من الفشل في } \\
\hline & & 32 & 209.45 & 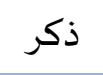 & \\
\hline \multirow{2}{*}{0.872} & \multirow{2}{*}{5834.500} & 371 & 202.27 & أنثى أنى & \multirow{2}{*}{ قلق المستقبل } \\
\hline & & 32 & 198.83 & 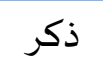 & \\
\hline
\end{tabular}

يتضح من جدول (8) ما يلي:

1- مستوى المعنوية للأبعاد الخمسة (القلق المتعلق بالمشكلات الحياتية، قلق الصحة وقلق الموت، القلق الذهني، اليأس من المستقبل، الخوف والقلق من الفشل في المستقبل) تراوحت من (0.438) إلى (0.959)

وجميعها أكبر من (0.05)، وهذا يدل على عدم وجود اختلافات في الوحدات محل الدراسة لجميع الأبعاد. 2- مستوى المعنوية لقلق المستقبل بشكل عام (0.872) وهوأكبر من (0.05)، وهذا يدل على عدم وجود فروق في درجة قلق المستقبل تُعزى لمتغير الجنس (ذكور، إناث).

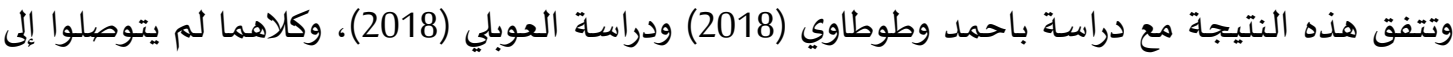
وجود فروقًا في درجة قلق المستقبل تعزى لمتغير الجنس. كما تختلف هذه النتيجة مع دراسة عابد (2015)، التي وجدت أن هناك فروقًا في قلق المستقبل لصالح الذكور، ودراسة الرفاعي (2020)، التي وجدت فروقةًا في قلق المستقبل لصالح الإناث.

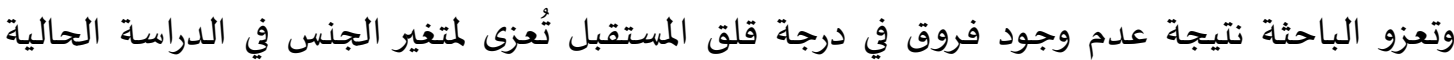

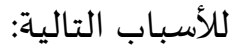
1- تعرّض كلا الجنسين لنفس الظروف الراهنة مع وجود جائحة كورونا (COVID-19) وتأثيراتها النفسية والاجتماعياة. 2- معايشة كلا الجنسين للتحوّل في النظمم التعليمية في المملكة العربية السعودية من النظام التقليدي في الفصول الواقعية، إلى نظام التعليم عن بُعد، ومواجهتهم لجميع التحديات بنفس القدرل 
نتيجة السؤال الثالث: "هل توجد فروق دالة إحصائيًا في درجة قلق المستقبل في ضوء التحول إلى التعليم عن بُعد أثناء جائحة كورونا (COVID-19) تعزى لمتغير التخصص (علمي - ادبي) لدى طلبة الصئية الصفين الثاني والثالث الثانوي بالمدينة المنورة؟ باءك كورنا

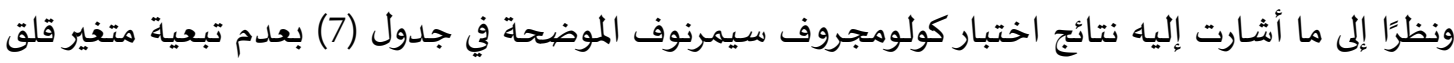

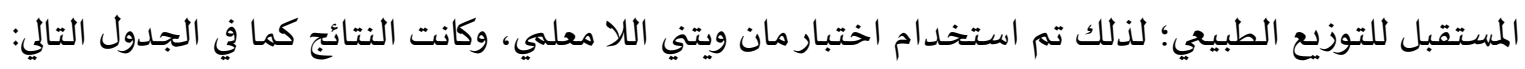
جدول (9) نتائج اختبار مان ويتني لحساب الفروق في درجة قلق المستقبل التي تُعزى لمتغير التخصص ولتئي

\begin{tabular}{|c|c|c|c|c|c|}
\hline المعنوية & قيمة مان & حجم العينة & متوسط & التخصص & البُعد \\
\hline \multirow{2}{*}{0.041} & \multirow{2}{*}{17902.000} & 208 & 213.43 & علمي & \multirow{2}{*}{ القلق المتعلق بالمشكلات الحياتية } \\
\hline & & 195 & 189.81 & أدبي & \\
\hline \multirow{2}{*}{0.134} & \multirow{2}{*}{18534.000} & 208 & 210.39 & 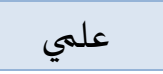 & \multirow{2}{*}{ قلق الصحة وقلق الموت } \\
\hline & & 195 & 193.05 & أدبي أدبي & \\
\hline \multirow{2}{*}{0.329} & \multirow{2}{*}{19142.000} & 208 & 196.53 & علمي & \multirow[t]{2}{*}{ القلق الذهني } \\
\hline & & 195 & 207.84 & أدبي & \\
\hline \multirow{2}{*}{0.783} & \multirow{2}{*}{19958.500} & 208 & 200.45 & 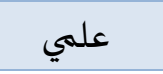 & \multirow{2}{*}{ اليأس من المستقبل } \\
\hline & & 195 & 203.65 & أدبي & \\
\hline \multirow{2}{*}{0.590} & \multirow{2}{*}{19655.500} & 208 & 199.00 & علمي & \multirow{2}{*}{ الخوف والقلق من الفشل في } \\
\hline & & 195 & 205.20 & أدبي & \\
\hline \multirow{2}{*}{0.790} & \multirow{2}{*}{19968.500} & 208 & 203.50 & 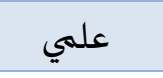 & \multirow{2}{*}{ قلق المستقبل } \\
\hline & & 195 & 200.40 & أدبي & \\
\hline
\end{tabular}

يتضح من جدول (9) ما يلي:

1- مستوى المعنوية لبُعد القلق المتعلق بالمشكلات الحياتية المستقبلية (0.041)، وهو أقل من (0.05)، وهذا يدل على اختلاف الوحدات محل الدراسة حسب نتائج القلق المتعلق بالمشكلات الحياتية المستقبت بلمبلية.

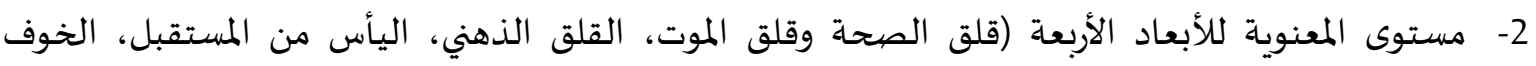

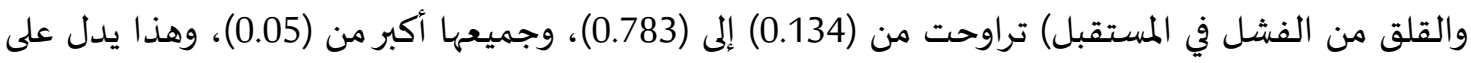
عدم اختلاف الوحدات محل الدراسـة للأبعاد الأبربعة.

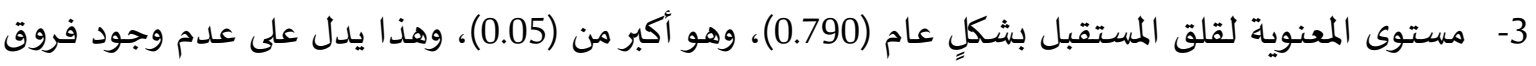

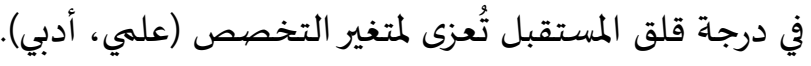

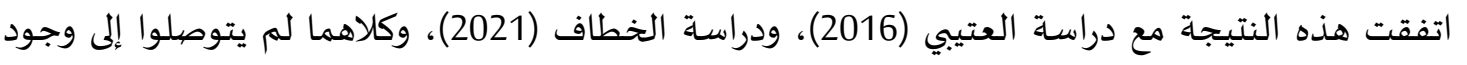

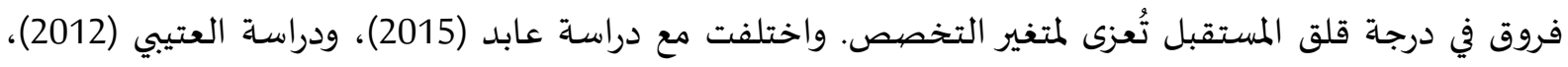

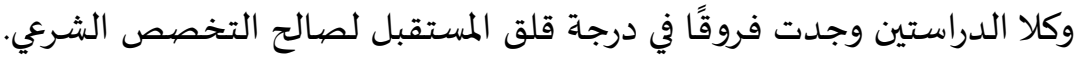
وترى الباحثة أن:

1- هناك اختلاف في درجة قلق المستقبل بالنسبة لبُعد القلق المتعلق بالمشكلات الحياتية المستقبلية بين التخصصين (العلمي، الأدبي) لصالح التخصص العلمي، وقد تعزو الباحثة ذلك الاختلاف إلى الاحتياج 
الميداني للتخصص العلمي في تطبيق بعض المواد بشكلٍ عمليّ، بعكس التخصص الأدبي الذي لا يستدعي ذلك، فقد يكون ذلك عاملًا يشكل الخوف كمشكلة مستقبلية، تتمثل في عدم القدرة على إتقان المهارة التطبيقية للمواد العلمية. 2- تدل هذه النتيجة على عدم تأثير متغير التخصص واختلافه بين أفراد العينة في درجة قلق المستقبل للطلبة بشكلٍ عام.

نتيجة السؤال الرابع: "هل توجد فروق دالة إحصائيًا في درجة قلق المستقبل في ضوء التحول إلى التعليم عن

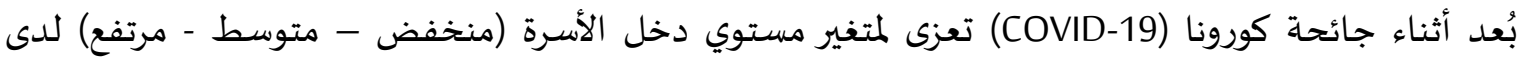
طلبة الصفين الثاني والثالث الثانوي بالمدينة المنورة؟

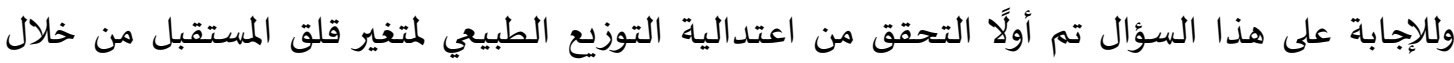

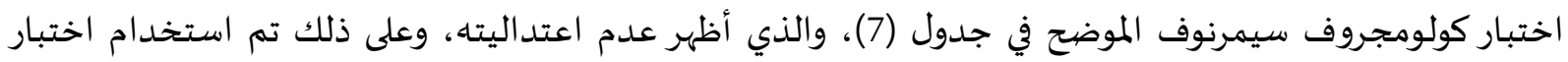
كروكسال ويلز، وكانت النتائج كما في الجدول الآتي: جدول (10) نتائج اختبار كروسكال ويلز لحساب الفروق في درجة قلق المستقبل التي تُعزى لمتغير مستوى دخل الأسرة

\begin{tabular}{|c|c|c|c|c|c|}
\hline المعتوى & قيمة كروسكال & العينة & متوسط الرتب & مستوي دخل & البُعد \\
\hline \multirow{3}{*}{0.988} & \multirow{3}{*}{0.025} & 120 & 201.23 & منخفض & \multirow{3}{*}{ القلق المتعلق بالمشكلات } \\
\hline & & 176 & 201.63 & متوسط & \\
\hline & & 107 & 203.49 & مرتفع & \\
\hline \multirow{3}{*}{0.481} & \multirow{3}{*}{1.463} & 120 & 194.08 & منخفض & \multirow{3}{*}{ قلق الصحة وقلق الموت } \\
\hline & & 176 & 200.96 & متوسط & \\
\hline & & 107 & 212.59 & مرتفع & \\
\hline \multirow{3}{*}{0.925} & \multirow{3}{*}{0.156} & 120 & 199.03 & منخفض & \multirow{3}{*}{ القلق الذهني } \\
\hline & & 176 & 204.39 & متوسط & \\
\hline & & 107 & 201.39 & مرتفع & \\
\hline \multirow{3}{*}{0.896} & \multirow{3}{*}{0.219} & 120 & 204.01 & منخفض & \multirow{3}{*}{ اليأس من المستقبل } \\
\hline & & 176 & 198.94 & متوسط & \\
\hline & & 107 & 204.78 & مرتفع & \\
\hline \multirow{3}{*}{0.158} & \multirow{3}{*}{3.687} & 120 & 218.98 & منخفض & \multirow{3}{*}{ الخوف والقلق من الفشل } \\
\hline & & 176 & 194.77 & متوسط & \\
\hline & & 107 & 194.86 & مرتفع & \\
\hline \multirow{3}{*}{0.930} & \multirow{3}{*}{0.146} & 120 & 202.96 & منخفض & \multirow[t]{3}{*}{ قلق المستقبل } \\
\hline & & 176 & 199.61 & متوسط & \\
\hline & & 107 & 204.85 & مرتفع & \\
\hline
\end{tabular}

يتضح من جدول (10) ما يلي: 
1- مستوى المعنوية للأبعاد الخمسة (القلق المتعلق بالمشكلات الحياتية، قلق الصحة وقلق الموت، القلق الذهني،

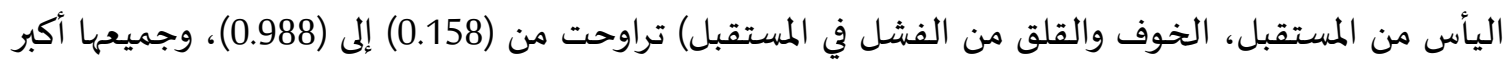

من (0.05)، وهذا يدل على عدم اختلاف الوحدات محل الدراسة للأبعاد الخمسة.

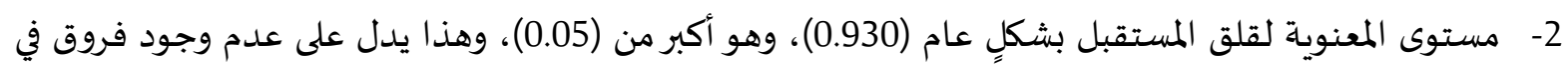

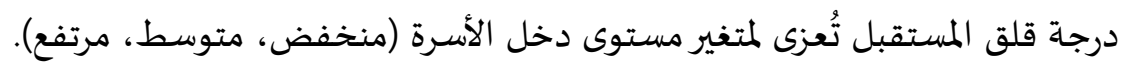

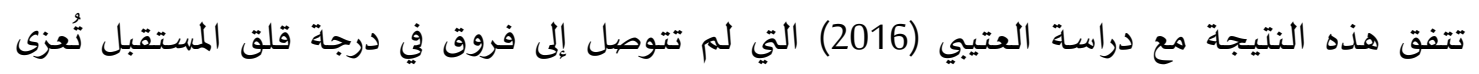

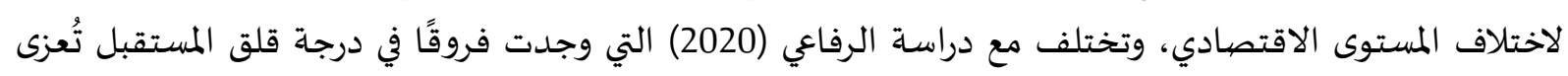

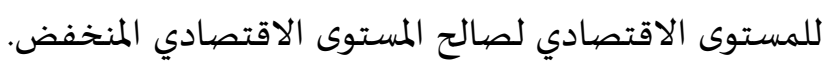
وتعزو الباحثة هذه النتيجة وهي عدم وجود فروق في درجة قلق المستقبل بحسب تفاوت المبت مستويات دخل الأسرة في الدراسة الحالية إلى الأسباب التالية:

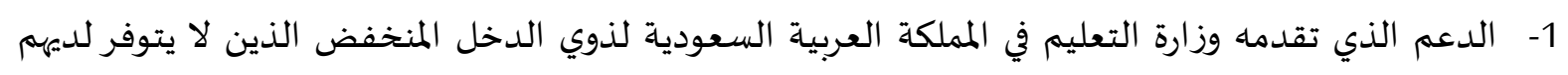

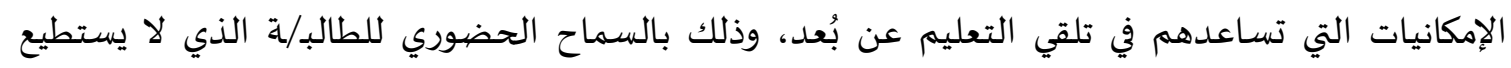

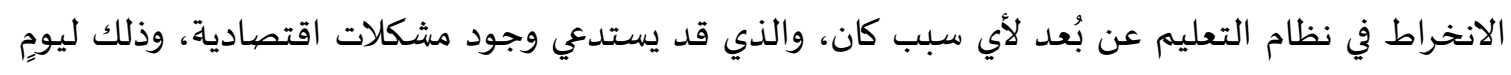

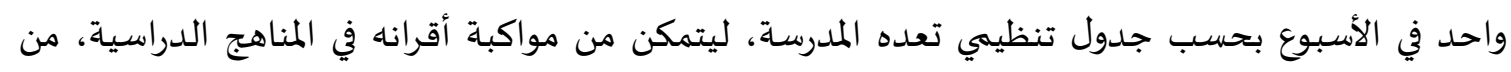

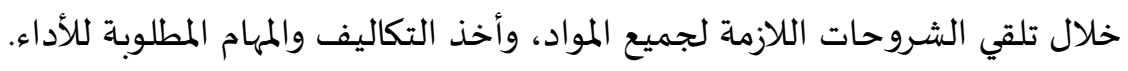
2- اتاحت وزارة التعليم لقنوات مجانياة، تبث شروحات تعليمية، لجميع المناهج الدراسية، ولمختلف والف المراحل الدراسية، وذلك تسهيلًا لجميع الطلبة على مواصلة التعليم.

ملخص نتائج الدراسة: 1- - وجود قلق المستقبل في ضوء التحول إلى التعليم عن بُعد أثناء جائحة كورونا (COVID-19) لدى طلبة الصفين

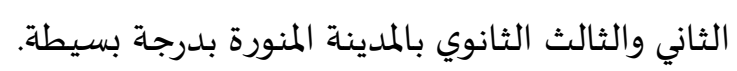

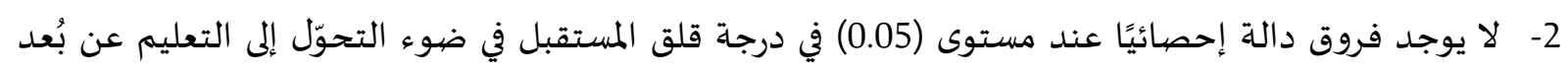

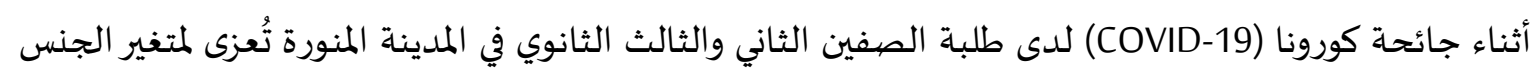

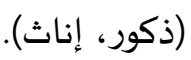
3- لا يوجد فروق دالة إحصائيًا عند مستوى (0.05) في درجة قلق المستقبل في ضوء التحوّل إلى التعليم عن بُعد أنداث

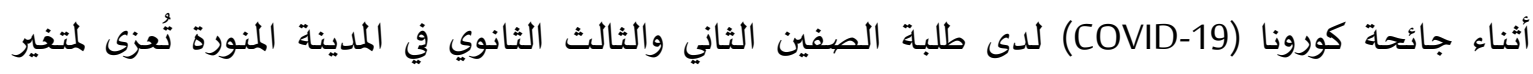
التخصص (علمي، أدبي).

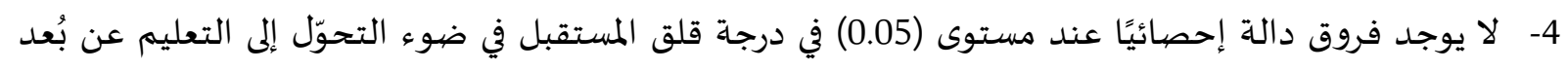

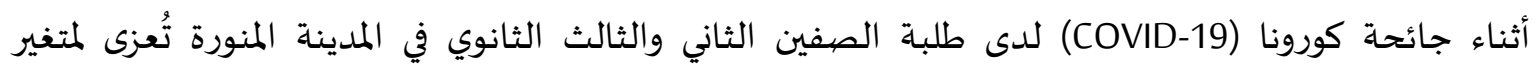

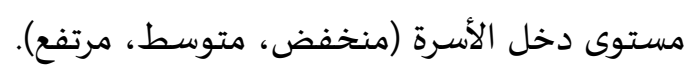




\section{توصيات الدراسة ومقترحاتها.}

في ضوء النتائج التي أسفرت عنها الدراسـة الحالية توصي الباحثة وتقترح ما يلي:

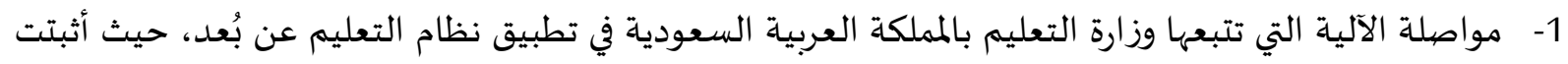
نتائج الدراسة الحالية عدم تأثيره بشكلٍ كبير على مستويات قلق المستقبل لدى لدئ طلاب وطالبات المرحلة الثانوية. 2- توجيه دور الإرشاد النفسي المدرسي وزيادة فاعليته، نحو التخفيف من القلق المتعلق بالمشكلات الحياتية

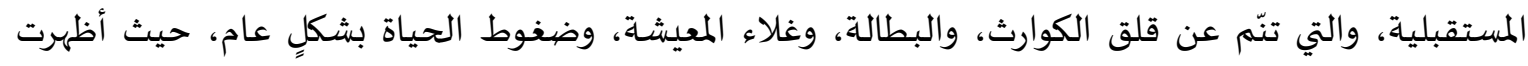

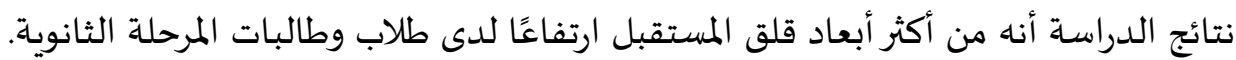

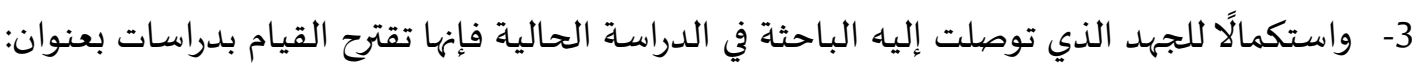

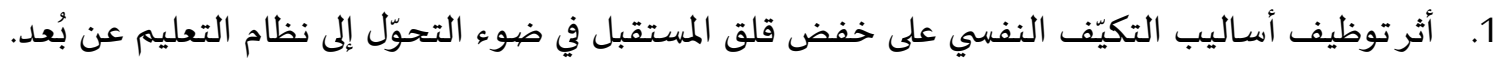
2. نمذجة العلاقة بين الصمود النفسي وقلق المستقبل ومستوى الإنجاز في ضوء التحوّل إلى نظام التعليم عن بُعد.

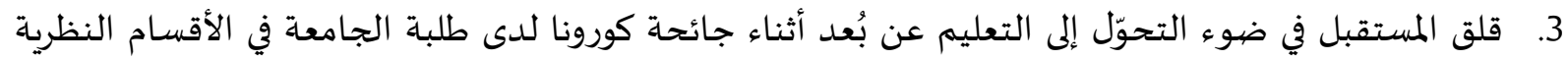

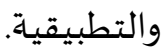

قائمة المراجع.

أولاً - المراجع بالعربية:

- إبراهيم وآخرون. (1973). المعجم الوسيط (ط. (2.). دار المعارف.

- با حمد، جويدة؛ وطوطاوي، مبدوعاة. (2018). قلق المستقبل لدى تلاميذ التعليم عن بعد المتمدرسين بمركز تيزي وزو وبجاية. مجلة العلوم النفسية والتربوية، 7(2)، 393-406. - ـ البلادي، منى سعد حضيض. (2013). المشكلات السلوكية لدى طالبات المرحلة الثانوية بالمدينة المنورة ومعالجتها في ضوء التربية الإسلامية. رابطة التربويون العرب، (36)، 153-223.

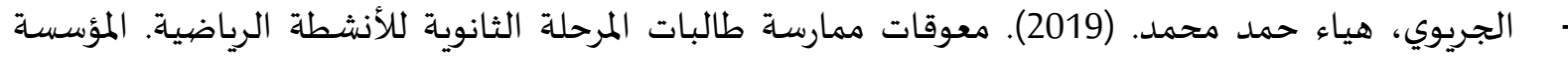
العربية للبحث العلمي والتنمية البشرية، (20)، 251-315. الحربي، تهاني محمد. (2018). قلق المستقبل وعلاقته بتقدير الذات ومستوى الطموح لدى طالبات المرحلة الثانوية في مدينة الرياض. مجلة الجامع في الدراسات النفسية والعلوم التربوية، (8)، 68-88. الخطاف، نهى سليمان. (2021). قلق المستقبل لدى عينة من طالبات المرحلة الثانوية في بريدة. مجلة العلوم التربوية والاجتماعياة، 1(5)، 26-54. - - مفاجي، سامي. (2015). التعليم المفتوح والتعلم عن بعد أساس للتعليم الالكتروني. الأكاديميون للنشروالتوزيع.

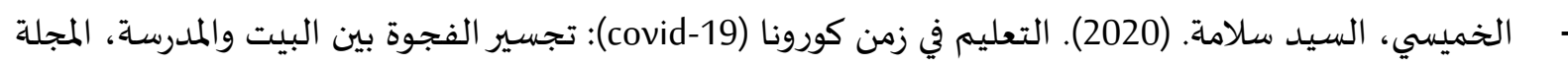
الدولية للبحوث في العلوم التربوية، 3(4)، 51-73. الدهشان، جمال علي. (2020). مستقبل التعليم بعد جائحة كورونا: سيناريوهات استشرافية. المجلة الدولية للبحوث في العلوم التربوية، 3(4)، 105-169. - الرفاعي، ليال عبد السلام. (2020). قلق المستقبل لدى الشباب الجامعيين بظل جائحة كورونا والأزمة الاقتصادية في لبنان. مجلة أوراق ثقافياة، 2(9). قلق المستقبل لدى الشّبّاب الجامعيين بظل المبل جائحة كورونا

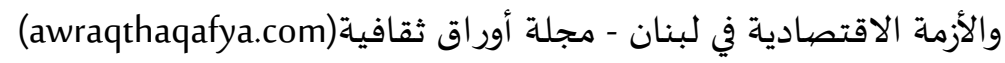


زهران، حامد عبد السلام. (2005أ). التوجياه والإرشاد النفسي (ط.4). عالم الكتب.

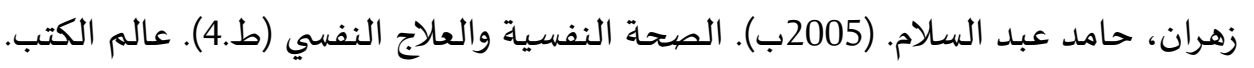

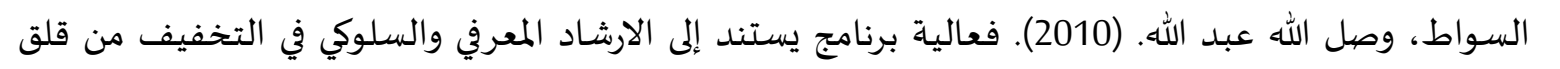

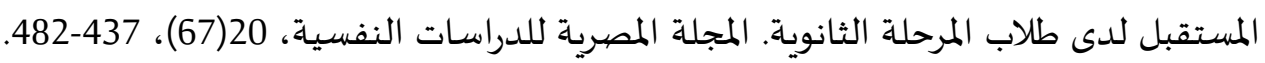

شقير، زينب محمود. (2005). مقياس قلق المستقبل. مكتبة الأنجلو المصرية.

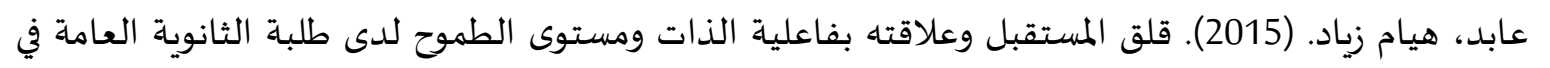
محافظة غزة [رسالة ماجستير غير منشورة]. الجامعة الإسلامياة في غزة. عامر، طارق عبد الرؤوف. (2018). التعليم عن بعد والتعليم المفتوح. دار اليازوري للنشر والتوزيع. العتيبي، ممدوح عوض. (2012). قلق المستقبل وعلاقته بالدافع للإنجاز وتقدير الذات لدى طارئ لاب المروحلة الثانوية بمحافظة الطائف [رسالة ماجستير غير منشورة]. جامعة الطائف.

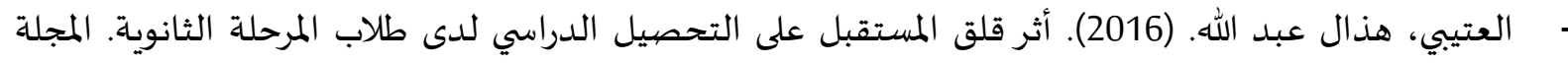
العلمية بكلية التربية بجامعة أسيوط، 32(4)، 426-458. العنزي، خالد الحميدي. (2010). إدراك القبول - الرفض الوالدي والأفكار اللاعقلانية وقلق المستقبل لدى عينة

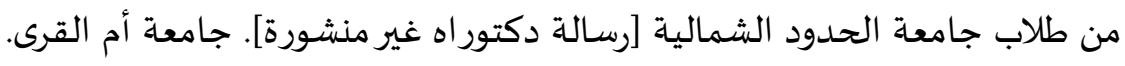

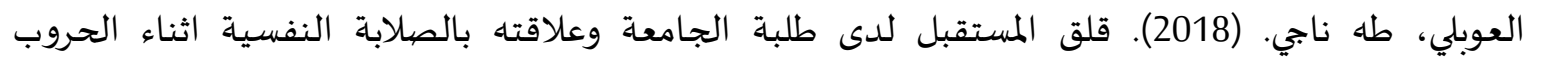

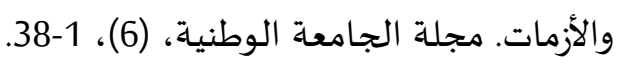
غنايم، مهني محمد. (2020). التعليم العربي وأزمة كورونا: سيناريوهات للمستقبل. المجلة الدولية للبحوث في العلوم التربوية، 3(4)، 75-104. قليوبي، محمد خالد. (2019). قلق المستقبل وعلاقته بدافعية الإنجازلدى عينة من طلاب البكالوريوس المقبلين

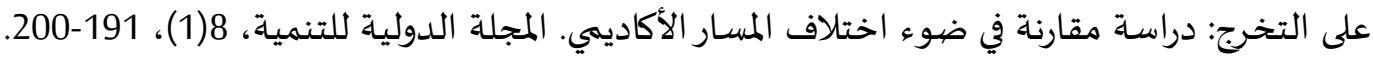
قناوي، شاكر عبد العظيم. (2020). جائحة كورونا والتعليم عن بعد: ملامح الأزمة وآثارها بين الواقع والمستقبل ماتل والتحديات والفرص. المجلة الدولية للبحوث في العلوم التربوية، 3(4)، 225-260. الكحيمي، وجدان؛ وحمام، فادية؛ ومصطفى، علي. (2011). الصحة النفسية للطفل والمراهق (ط.4). مكتبة

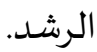
كفافي، علاء الدين. (2005). الصحة النفسية والإرشاد النفسي (ط.2). دار النشر الدولي للنشر والتوزيع.

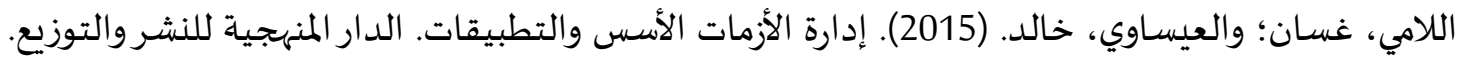

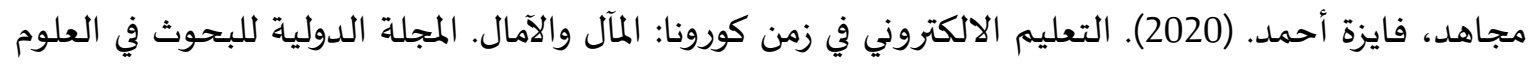
التربوية، 3(4)، 305-335. مرض فيروس كورونا (كوفيد-19): سؤال وجواب. (2019). منظمة الصحة العالمية، تم الاسترجاع في 15 نوفمبر https://www.who.int/ar/emergencies/diseases/novel-coronavirus-2019/advice-for-public/q-acoronaviruses المشيخي، غالب محمد. (2009). قلق المستقبل وعلاقته بكل من فاعلية الذات ومستوى الطموح لدى عينة من طلاب جامعة الطائف [رسالة دكتوراه غير منشورة]. جامعة الطائف. 
المجلة العربية للعلوم ونثر الأبحاث ـ مجلة العلوم التربوية والنفسية ـ المجلد السادس ـ العدد الثاني ـ يناير 2022م

- وادة، فتحي. (2019). قلق المستقبل وعلاقته بفاعلية الذات لدى عينة من طلبة جامعة الوادي. مجلة العلوم النفسية والتربوية، 5(4)، 69-90.

\section{ثانياً- المراجع بالإنجليزية:}

- Akyildiz, S. (2020). College Students' Views on the Pandemic Distance Education: A Focus Group Discussion. International Journal of Technology in Education and Science, 4(4), 322-334.

- Hasan, N., \&Bao, Y. (2020). Impact of "e-Learning crack-up" perception on psychological distress among college students during COVID-19 pandemic: A mediating role of "fear of academic year loss". Children and Youth Services Review, 118, 1-9.

- Zaleski, Z. (1996). Future Anxiety: concept, measurement, and preliminary research. Person individual differences, 21(2), 165-174. 